Open Access

\title{
Assessing the evidence on the differential impact of menthol versus non-menthol cigarette use on smoking cessation in the U.S. population: a systematic review and meta-analysis
}

\author{
Mimi M. Kim ${ }^{*}$ (ID and Geoffrey M. Curtin
}

\begin{abstract}
Background: The potential impact of menthol versus non-menthol cigarette use on smoking behaviors is an intensely scrutinized topic in the public health arena. To date, several general literature reviews have been conducted, but findings and conclusions have been discordant. This systematic review followed PRISMA guidelines to examine the Key Question, "Does menthol cigarette use have a differential impact on smoking cessation compared with non-menthol cigarette use?"

Methods: Six databases-Cochrane Central Register of Controlled Trials, Cochrane Database of Systematic Reviews, Database of Abstracts of Reviews of Effects, MEDLINE, Embase and Psyclnfo-were queried from inception to June 12, 2020. Articles comparing menthol versus non-menthol cigarette smokers in terms of at least one predefined smoking cessation outcome were included. Risk of bias was assessed using the Agency for Healthcare Research and Quality Evidence-Based Practice Center approach. A random-effects model utilizing the DerSimonian and Laird method to pool adjusted odds ratio was applied. Variations among pooled studies were assessed using Cochran's $Q$ statistic, and heterogeneity was quantified using the inconsistency index $\left(I^{2}\right)$.
\end{abstract}

Results: Forty-three demographically adjusted studies (22 rated "good", 20 rated "fair", and one study rated "poor" individual study quality) comparing menthol and non-menthol smokers were qualitatively synthesized across the following measures (study count; strength of evidence): duration of abstinence (2; low); quit attempts (15; insufficient); rate of abstinence/quitting (29; moderate); change in smoking quantity/frequency (5; insufficient); and, return to smoking/relapse ( 2 ; insufficient). Overall, the qualitative synthesis failed to show a consistent trend for an association between menthol cigarette use and smoking cessation across outcomes. Meta-analyses found no difference between menthol and non-menthol cigarette use and either quit attempts or abstinence.

\footnotetext{
* Correspondence: kimm1@rirt.com

Scientific \& Regulatory Affairs, RAI Services Company, 401 North Main Street, Winston-Salem, NC 27101, USA
} 
Conclusions: Given the lack of consistency or statistical significance in the findings_combined with a "low" overall strength of evidence grade, based on deficiencies of indirectness and inconsistency - no consistent or significant associations between menthol cigarette use and smoking cessation were identified. Recommendations for future studies include increased focus on providing longitudinal, adjusted data collected from standardized outcome measures of cessation to better inform long-term smoking cessation and menthol cigarette use. Such improvements should also be further considered in more methodologically rigorous systematic reviews characterized by objectivity, comprehensiveness, and transparency with the ultimate objective of better informing public health and policy decision making.

Keywords: Smoking, Menthol cigarettes, Systematic reviews, Meta-analysis, Smoking cessation

\section{Background}

Currently, the proportion of smokers who use menthol cigarettes is higher among youth than among adults, with about three out of ten adult cigarette smokers choosing to smoke menthol cigarette brands [1]. Based on data from the U.S. Centers for Disease Control [2], rates of adult cigarette smoking have steadily declined over the last half century, from $42 \%$ in 1965 to $17 \%$ in 2014. Despite this overall decline in smoking, the Substance Abuse and Mental Health Services Administration [3] has noted that menthol cigarette use seems to be characterized by a contradictory upward trend among younger adults, females, males, Hispanics, and Asians. Thus, trends in smoking are inconsistent between menthol and non-menthol cigarette smokers.

In recent years, the potential impact of menthol versus non-menthol cigarette use on smoking behaviors has been an intensely scrutinized topic in the public health arena. More recently, the issue has been brought to the forefront of tobacco policy and decision making, as evidenced by the Food and Drug Administration's (FDA) recently-declared intent to explore a ban on mentholated tobacco products. Given the FDA's own commitment to evidencedbased actions [4], there is a clear need for the potential associations between menthol cigarettes and smoking behaviors to be explored scientifically. To date, several narrative reviews have been conducted. However, study methods and the included individual publications have varied, and conclusions have been discordant [5-7]. Some of the discord may reflect the complicated constructs related to smoking behaviors and the varying measurements across studies $[8,9]$.

A recent meta-analysis by Smith and colleagues [10] concluded that, among Blacks/African Americans in the U.S. (one sample including respondents from Canada), menthol smokers had approximately $12 \%$ lower odds of smoking cessation compared to non-menthol smokers. However, the meta-analysis was not based on a full, PRISMA-guided systematic review of the available evidence. A second systematic review by Smith et al. [9] found that both men and women exhibit minimal switching between menthol and non-menthol cigarettes, suggesting that preference is established early in an individual's smoking trajectory. However, these findings were based on a single included study in the review of smoking initiation, and therefore conclusions are limited in generalizability. Similarly, a systematic review by Villanti et al. [7] reported an association between menthol cigarette smoking and increased initiation among youth, increased dependence especially among youth, and reduced cessation among non-Hispanic Whites and racial and ethnic subgroups. However, the validity of these findings are undermined by the failure to apply an adequate appraisal tool-such AMSTAR 2 [8] which would have identified significant methodological insufficiencies.

Given the methodological deficiencies in the current evidence base, the purpose of our review was to systematically assess the potential association between menthol cigarette use and smoking cessation, with a strict methodological focus to the measures and methods used by the included studies.

Further, given that smoking behaviors can vary across different population subgroups-suggesting that both individual and environmental factors influence smoking [11, 12]-it is essential that factors that influence smoking behaviors be considered to the extent possible based on available data. To this end, this review applied the Socio-Ecological Model created by McLeroy et al. [13] to guide consideration of the interrelationships between individuals and their social (micro-), physical (meso-), and policy (macro-) environments. The socio-ecological model includes three main levels of factors that influence an individual's smoking behaviors: characteristics of the individual ("micro"); characteristics of the individual's social environment ("meso"); and characteristics of the systems-level environment in which the individual exists ("macro"). Our review also attempted to quantitatively synthesize the evidence with meta-analyses; to the best of the authors' knowledge, quantitative synthesis of data from a systematic review has not been previously conducted for this evidence base. 


\section{Methods \\ Overview}

The methods used for this systematic review followed PRISMA guidelines and were applied to a larger literature search strategy of the association between menthol cigarette use and three smoking behaviors-initiation, cessation, and dependence-of which cessation is the focus of this analysis. Specifically, current results assess the Key Question (KQ), "Does menthol cigarette use have a differential impact on smoking cessation compared to non-menthol cigarette use?" The protocol for this systematic review was registered with the PROSPERO international prospective register of systematic reviews on March 22, 2016 and updated on January 10, 2019. The record is available at: https://www.crd.york.ac. uk/prospero/display_record.php?RecordID=119301.

\section{Literature search strategy}

The literature searches were conducted by an Information Specialist. Search terms were developed using text words related to the associations between menthol cigarette use and cessation of cigarette smoking. The search strategy included using synonyms of search terms, truncation, wild card symbols, Boolean logic, proximity operators, and limits to focus the search towards the most relevant clinical literature (see SUPPLEMENTAL SECTION 1: Literature Search Strategy).

The following online databases were searched for relevant articles published from inception to 14 December 2018 (for the initial literature search) and from 01 January 2018 to 12 June 2020 (for the updated literature search): Cochrane Central Register of Controlled Trials, Cochrane Database of Systematic Reviews, Database of Abstracts of Reviews of Effects, MEDLINE, Embase and PsycInfo.

The initial literature search (from inception to $14 \mathrm{De}$ cember 2018) identified 853 potentially relevant articles, with 838 articles from online databases and 15 additional articles through other sources. An updated literature search (from 01 January 2018 to 12 June 2020) identified an additional 358 potentially relevant articles; however, 149 of the articles were duplicate articles across the two searches, due to a required overlap in the two search timeframes (searches are best conducted from the first of the year). Thus, 209 unique articles were identified in the update literature searching, bringing the total of potentially relevant articles to 1062. After independent review of titles and abstracts by two members of the research team, 603 references were excluded, resulting in 459 articles being screened at the full-text level. An additional 324 articles were excluded at the full-text level (provided in SUPPLEMENTAL SECTION 2: Studies excluded at full-text level screening (with reason for exclusion)), resulting in 135 relevant articles eligible for inclusion; 73 studies (eight of which were reported in paired studies) evaluated the association between menthol cigarette smoking and smoking cessation or cessation-related outcomes (Fig. 1). The weighted overall kappa for inter-rated reliability at full-text screening was 0.96 for the initial literature search, and 0.95 for the updated literature search.

\section{Eligibility criteria}

Eligibility criteria were developed according to the PICO framework and are presented in Table 1. Studies of solely non-U.S. residents were excluded on the basis of variations in national tobacco legislation limiting the generalizability of such studies to the U.S. population.

\section{Data extraction}

Data were extracted and managed through DistillerSR (Evidence Partners, Ottawa, Canada). Articles were initially screened at the title/abstract level; full-text articles were obtained for studies not excluded based on the title/abstract alone. Two reviewers independently screened articles based on the inclusion/exclusion criteria. Any discrepancies between the two were resolved in a joint-reviewer decision. Any unresolved disagreements were adjudicated by a third clinical reviewer; reasons for exclusions were documented.

Data were independently extracted by one research associate and checked by a second research associate. Discrepancies were resolved through discussion and included a third team member when necessary. Data extraction forms were created in DistillerSR.

\section{Study quality assessment Study quality rating}

A random and sufficient sample of included studies was assessed independently by two members of the review team. The level of agreement between those researchers was evaluated based on the mean difference in scores between the two reviewers. The mean difference was 0.25 points ( $95 \% \mathrm{CI},-0.53$ to 1.03 ), indicating that, on average, reviewers had a high level of agreement that the true mean difference was no greater than one point on the scale. The difference in score across studies was distributed normally, suggesting no systematic bias. Based on the high level of agreement, the ratings were not found to be subject to individual reviewer bias, and a single reviewer reviewed the remaining included studies.

\section{Downs and Black checklist}

The quality of the studies included in this systematic review was assessed at the study level using the Downs and Black checklist [14]. The instrument was used as reported in the original publication, with only one adaptation of the power question as to whether the study was 


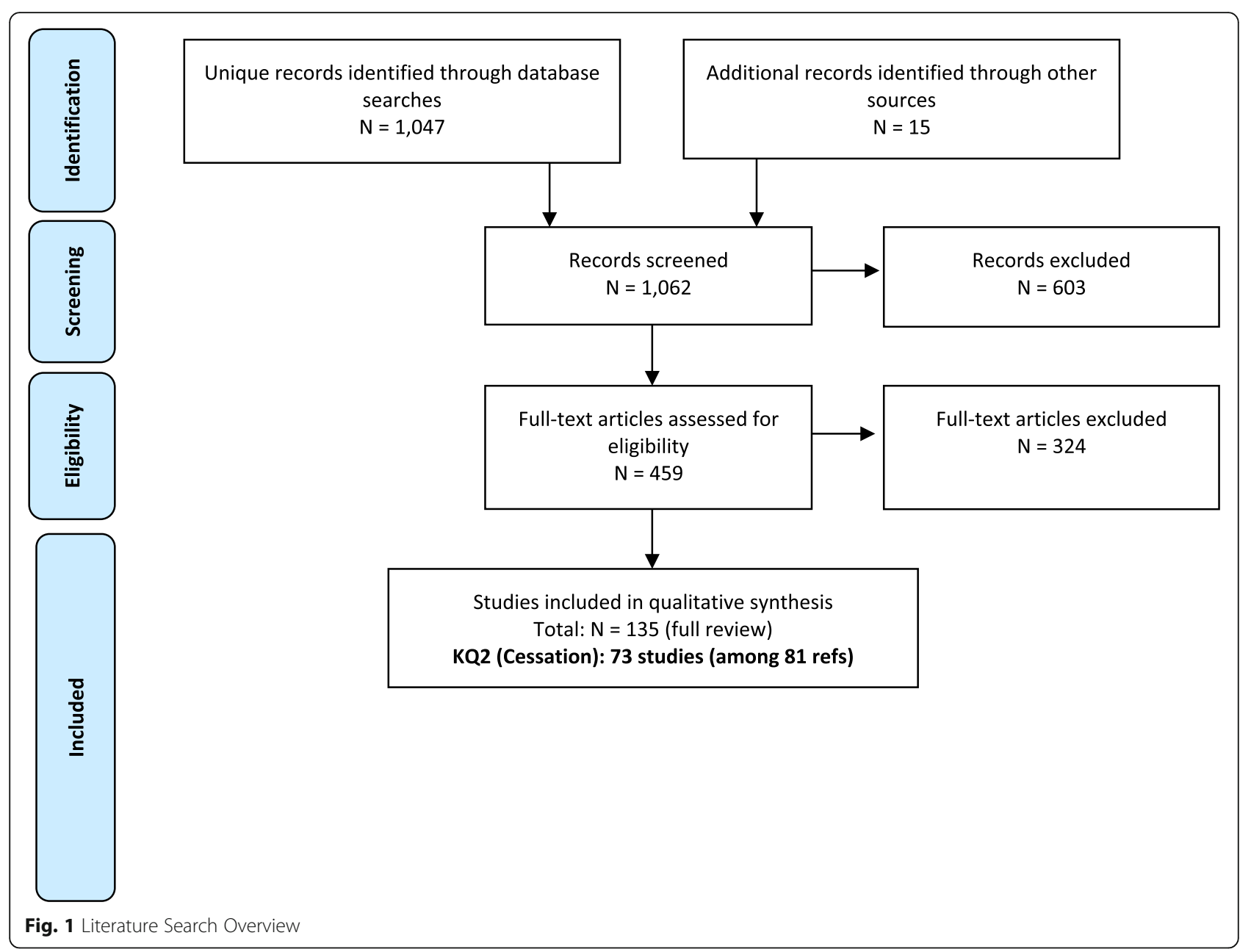

Table 1 Inclusion and Exclusion Criteria for Key Questions (KQs)

\begin{tabular}{|c|c|c|}
\hline & Inclusion Criteria & Exclusion Criteria \\
\hline Population & $\begin{array}{l}\text { - Youth and adults } \\
\text { - Current or former smokers with explicit use of (or stated preference for) } \\
\text { menthol or non-menthol cigarettes; studies of non-smokers were eligible if } \\
\text { they reported a measure of initiation } \\
\text { - United States residents }\end{array}$ & $\begin{array}{l}\text { - Studies of never-smokers at any time point } \\
\text { - Studies of only non-United States residents }\end{array}$ \\
\hline Comparisons & $\begin{array}{l}\text { - Menthol versus non-menthol } \\
\text { - Delivery of nicotine via traditional cigarettes }\end{array}$ & $\begin{array}{l}\text { - Studies reporting only menthol or non-menthol or } \\
\text { not directly comparing menthol with non-mentho } \\
\text { - Studies of non-traditional tobacco delivery }{ }^{\mathrm{a}}\end{array}$ \\
\hline Outcomes & $\begin{array}{l}\text { - Duration of abstinence; quit attempts (any quit attempts; number of quit } \\
\text { attempts per person); rate of abstinence/quitting (including but not limited } \\
\text { to prolonged abstinence [PA], point prevalence abstinence [PPA], } \\
\text { identifiable cigarette type [menthol versus non-menthol] smoked before } \\
\text { quitting, and being a former smoker [versus current smoker]); Change in } \\
\text { smoking quantity/frequency; return to smoking/relapse }\end{array}$ & - Any other outcomes \\
\hline $\begin{array}{l}\text { Study } \\
\text { Designs }^{\mathrm{b}}\end{array}$ & $\begin{array}{l}\text { - Randomized and non-randomized controlled trials } \\
\text { - Cross-sectional, case-control, and cohort studies } \\
\text { - Letters and editorials containing original data not available elsewhere were } \\
\text { eligible }\end{array}$ & $\begin{array}{l}\text { - Reviews, case reports, editorials, and letters not } \\
\text { containing original data }\end{array}$ \\
\hline
\end{tabular}

\footnotetext{
E.g., vaporizers, e-cigarettes, hookahs/water pipes

${ }^{\mathrm{b}}$ Reclassification of included trials as cross-sectional or cohort depending on the eligible data as follows: if only baseline data used from a trial, it was considered

a cross-sectional study; if any post-baseline measurement data was used, it was considered it a cohort
} 
adequately powered (yes/no). The maximum achievable score for a study was 28 , and score ranges were grouped into the following four quality levels: "excellent" (26-28); "good "(20-25); "fair" (15-19); and "poor" ( $\leq 14)$. When data from a single study were reported in multiple references, all references were considered to determine an overall rating for the study.

\section{Assessment of confounding}

A list of potential confounding factors was identified a priori based on evidence and expert opinion from members of the research team and external advisors. Variables that individual study authors considered were recorded for additional post hoc consideration.

This review assessed evidence that adequately controlled for confounding bias according to the predetermined confounders of age, race/ethnicity, and gender. Studies that also adjusted for additional potential meso(e.g., living with a smoker) or macro-level factors (e.g., cigarette taxes) were flagged for inclusion in sensitivity analyses. Studies with potential overadjustment or adjustment for factors in the causal pathway were also flagged for further examination in sensitivity analyses.

\section{Conceptual framework}

This review applied the Socio-Ecological Model [13] to guide consideration of the interrelationships between individuals and their social (micro-), physical (meso-), and policy (macro-) environments.

\section{Outcomes and related psychometrics}

Included studies reported on at least one of the following cessation-or cessation-related-outcomes: duration of abstinence, quit attempts (any quit attempts; number of quit attempts per person), rate of abstinence/quitting, change in smoking quantity/frequency, and return to smoking/relapse. Recognizing that not all the outcome measures are likely to be equally valid and reliable, this review examined the following Contextual Question (CQ) to provide additional information and context for the results, "Have measures used to examine cigarette smoking cessation been psychometrically assessed as valid and reliable?" The applied scoring approach was informed by the IARC Handbook of Cancer Prevention [15].

\section{Data analysis}

The strongest evidence to assess whether menthol cigarette use has a differential impact on smoking cessation compared to non-menthol cigarette use would be expected to be provided by longitudinal analyses that adjusted or controlled for key confounding factors - age, race/ethnicity, and gender - by inclusion criteria, modeling, or stratification. Consequently, all studies that controlled for, at minimum, age, gender, and race/ethnicity were qualitatively synthesized.

Longitudinal analytic results were considered the highest available evidence and, as such, were weighed more heavily in the strength of evidence analysis and qualitative synthesis below. In the absence of longitudinal analytic results, the highest level of available evidence was synthesized according to studies that controlled for the predefined demographic factors.

\section{Statistical significance}

Estimates of the difference between menthol and nonmenthol smokers are presented with the best measure of precision (i.e., 95\% confidence intervals) or statistical significance (i.e., $p$-value) reported in the included studies. The words "significant" and "significantly" are used herein to indicate statistical significance (i.e., $p<0.05$ and/or confidence interval excludes 1.0).

\section{Meta-analysis}

For the meta-analyses, all included studies were controlled, at minimum, for age, gender, race/ethnicity. Menthol cigarette use was defined as either self-reported menthol use, current use, usual cigarette/brand used, or remaining with menthol cigarettes through the length of the study. Subgroup analysis was conducted to compare differences between study designs (prospective cohort and cross-sectional designs in abstinence [no duration]) and differences in measures (past year and ever quit attempt [ever quit attempts, any quit attempts between 2001 and 2005, and any quit attempts in the past 2, 3, or 5 years]). Further, sensitivity analyses were also completed according to race/ethnicity and abstinence verification (eCO verified), when possible. Pooled adjusted odds ratios (AORs) and 95\% confidence intervals (CIs) with two-sided $P$ values are reported from randomeffects models utilizing the DerSimonian and Laird method [16] to measure the likelihood of reporting having made a quit attempt and abstaining among menthol compared to non-menthol smokers. Variations among pooled studies were assessed using Cochran's Q statistic and heterogeneity was quantified using the inconsistency index $\left(\mathrm{I}^{2}\right)$. A $p$ value less than 0.10 was considered significant. $\mathrm{I}^{2}$ expresses the percent of variability in point estimates due to heterogeneity and results here follow the categories of low $\left(\mathrm{I}^{2}=25 \%\right)$, moderate $\left(\mathrm{I}^{2}=50 \%\right)$, and high $\left(\mathrm{I}^{2}=75 \%\right)$ [17]. All data were analyzed through Review Manager version 5.3 [18].

\section{Strength of evidence evaluation}

Recognizing the inherent limitations when assessing confidence in empirical conclusions based on observational data [19-22], the Agency for Healthcare Research and Quality (AHRQ) Evidence-Based Practice Center 
(EPC) approach - based largely on the methods developed by the Grading of Recommendations Assessment, Development and Evaluation (GRADE) Working Group [23] - was deemed acceptable for this review. Strength of evidence for this review was evaluated based on the four required domains:

1) Study limitations (previously called risk of bias) The degree to which included studies for a given outcome have a high likelihood of adequate protection against bias (ie, good internal validity), assessed through two main elements, study design and study conduct.

2) Directness - Whether evidence links interventions directly to a health outcome of specific importance for the review and, for comparative studies, whether the results are based on head-to-head comparisons.

3) Consistency - The degree to which included studies find either the same direction or similar magnitude of effect, as assessed by direction of effect and/or magnitude of effect.

4) Precision - The degree of certainty surrounding an effect estimate with respect to a given outcome, based on the sufficiency of sample size and number of events.

Reporting bias is one of the strength of evidence (SOE) domains typically assessed for systematic reviews, but the methods used to detect such bias are designed for use with controlled trials. Although observational studies may be susceptible to reporting bias, no comparable methods exist for assessing reporting bias for these study designs. As a result, reporting bias was not assessed for the purposes of this systematic review, which comprised of only observational studies, in accordance with methodological recommendations [24].

For this review, the SOE was assessed in two ways for each outcome measure. First, SOE was assessed for the studies that adjusted for the key confounders of age, race/ethnicity, and gender (through multivariable modeling, sample stratifications, or predefined study inclusion criteria). These results minimized the potential for confounding bias, represented the "best evidence," and thus may be more likely to represent the "true" association between menthol cigarette use and smoking behaviors.

Next, a sensitivity analysis was conducted to include the results from analyses that did not control for the key confounders. The unadjusted results reflected the effect of menthol cigarette use but allow all other variablesmeasured and unmeasured-to vary, potentially obscuring the actual effect of menthol smoking.

In both SOE assessments, measures with "acceptable" reliability and/or validity were weighed more heavily than the "inconclusive" measures (to minimize the impact of misclassification bias).

The final SOE judgment was necessarily qualitative but reflected a sound, reasoned weighing of domain ratings.

The overall strength of the body of evidence was graded as "high," "moderate," "low," or "insufficient" using the Evidence-Based Practice Center (EPC) approach (Table 2).

\section{Sensitivity analysis}

Additionally, three sensitivity analyses were conducted in order to evaluate the SOE, to include: limitation of the study pool to those that also adjusted for meso- and/ or macro-level variables; exclusions of "poor" quality studies (according to the Downs and Black study quality assessment); and exclusion of studies with potential overadjustment and/or inappropriate adjustment.

\section{Results}

A total of 73 studies, reported in 81 unique references, evaluated the potential associations between menthol cigarette use and smoking cessation. Adjusted studies were considered a higher level of evidence and, therefore, all subsequent analyses were restricted to studies that adjusted for key demographic characteristics. A total of 43 studies, reported in 47 unique references, provided adjusted data for relevant smoking cessation outcomes; complete study characteristics are shown in

Table 2 Strength of Evidence Grades and Definitions

\begin{tabular}{|c|c|c|}
\hline Grade & Interpretation & Description \\
\hline High & $\begin{array}{l}\text { Very confident that the estimate of effect lies close to } \\
\text { the true effect for this outcome. }\end{array}$ & $\begin{array}{l}\text { - The body of evidence has few or no deficiencies. } \\
\text { - We believe that the findings are stable, that is, another study would not } \\
\text { change the conclusions. }\end{array}$ \\
\hline Moderate & $\begin{array}{l}\text { Moderately confident that the estimate of effect lies } \\
\text { close to the true effect for this outcome. }\end{array}$ & $\begin{array}{l}\text { - The body of evidence has some deficiencies. } \\
\text { - We believe that the findings are likely to be stable, but some doubt remains. }\end{array}$ \\
\hline Low & $\begin{array}{l}\text { Limited confidence that the estimate of effect lies } \\
\text { close to the true effect for this outcome. }\end{array}$ & $\begin{array}{l}\text { - The body of evidence has major or numerous deficiencies (or both). } \\
\text { - We believe that additional evidence is needed before concluding either that } \\
\text { the findings are stable or that the estimate of effect is close to the true effect. }\end{array}$ \\
\hline Insufficient & $\begin{array}{l}\text { No evidence; unable to estimate an effect, or no } \\
\text { confidence in the estimate of effect for this outcome. }\end{array}$ & $\begin{array}{l}\text { No evidence is available or the body of evidence has unacceptable } \\
\text { deficiencies, precluding reaching a conclusion. }\end{array}$ \\
\hline
\end{tabular}


Table 3 Study, Data Set, and Sample Characteristics

\begin{tabular}{lllll}
\hline $\begin{array}{l}\text { First Author, } \\
\text { Year National } \\
\text { survey name } \\
\text { Quality rating }\end{array}$ & study & $\begin{array}{l}\text { Sampling / recruitment strategy; } \\
\text { Data collection period }\end{array}$ & $\begin{array}{l}\text { Brief summary of inclusion } \\
\text { criteria (including definition of } \\
\text { "smoker") }\end{array}$ & $\begin{array}{l}\text { Special } \\
\text { population }\end{array}$ \\
\hline
\end{tabular}

Alexander

et al., $2010 \quad$ NR:

[25]

TUS-CPS

Good

Azagba et al., National;

2019 [26] NR;

NYTS Cross-sectional

Fair

\author{
Stratified multistage probability \\ sample, civilian non-institutionalized \\ U.S. population; 2006-2007
}

A nationally representative sample of students enrolled in grades 6 through 12. The sampling universe consists of public and private school students in the 50 states and the District of Columbia. Primary sampling units are selected with probability proportional to the student enrollment in the PSU but giving disproportionate weight to Black, Asian, and Hispanic students. All students present in a selected classroom on the day of the interview are selected for the study; 2017-2018

\section{Blot et al., \\ 2011 [27] \\ None}

Fair
Southern states (Alabama, Arkansas, Florida, Georgia, Kentucky, Louisiana, Mississippi, North Carolina, South Carolina, Tennessee, Virginia, West Virginia); Govt;

Prospective cohort
Southern Community Cohort Study (SCCS), residents from southern U.S. states recruited from mailings to age, gender, and race-stratified random samples of the general population, predominately $(\sim 85 \%)$ at community health centers; March 2002 - September 2009

$\begin{array}{ll}\text { Cropsey et al., } & \text { Virginia; } \\ \text { 2009 [28] } & \text { Govt; } \\ \text { None } & \text { Prospective cohort } \\ \text { Fair } & \\ & \\ \text { Cubbin et al., } & \text { National; } \\ 2010 \text { [29]NHIS- } & \text { NR; } \\ \text { CCS } & \text { Cross-sectional } \\ \text { Good } & \end{array}$

$\begin{array}{ll}\text { D'Silva et al., } & \text { Minnesota; } \\ 2012[30] & \text { Govt; } \\ \text { None } & \text { Prospective cohort } \\ \text { Fair } & \end{array}$

Delnevo et al., National;

2010; Delnevo Govt;

et al., 2011 [31, Cross-sectional

32], 2010

TUS-CPS

Good

$\begin{array}{ll}\text { Fagan et al., } & \text { National; } \\ \text { 2007 [33] } & \text { Govt; } \\ \text { TUS-CPS } & \text { Cross-sectional } \\ \text { Fair } & \\ \text { Faseru et al., } & \text { Kansas; } \\ \text { 2013 [34] } & \text { Govt; } \\ \text { None } & \text { Prospective cohort }\end{array}$

Recruited through announcements and study flyers in prison housing units at a medium-maximum security female prison; June 2004-June 2006

Administered in 1992, 2000, 2005, and 2010 as a supplement to the NHIS that assesses issues related to cancer-related behaviors, screening, and risk assessment, including tobacco use and control; 2005

People who called the ClearWay Minnesota line; September 2009 July 2011, 7-month post-registration follow-up survey March 2010-February 2011

Stratified multistage probability sample, civilian non-institutionalized U.S. population; 2003, 2006-2007

Stratified multistage probability sample, civilian non-institutionalized U.S. population; 2003

Kick it at Swope-III (KIS-III trial), recruited at a community-based clinic serving a predominantly Black
Middle school and high school students who were current cigarette users, defined as smoking at least one out of the past 30 days. Smoking frequency was derived from the question "During the past 30 days, on how many days did you smoke cigarettes?" with the following possible answers: "0 days," "1 or 2 days," "3-5 days," "6-9 days," "10-19 days," "20-29 days," and "All 30 days."

Adults age 40-79 living in U.S. southern states. Ever-smokers ( $\geq 100$ lifetime cigs), continuing smokers (current smokers at baseline who reported smoking in the follow-up questionnaire), and former smokers at baseline. Respondents to the follow-up survey tended to be women, older, and of higher income and education level than non-respondents.

Adult women age $\geq 18$ who smoke $\geq 5 \mathrm{CPD}$, are not held in segregation from other prisoners and desired smoking cessation treatment.

Adults age 25-64 who selfidentified as Black, non-Hispanic/Latino, Hispanic/Latino, or White nonHispanic, smoked $\geq 100$ lifetime cigs and currently smoke every day (current smoker) or do not currently smoke (former smoker).

Adult smokers who registered for cessation counseling services.

White, Black and Hispanic eversmokers ( $\geq 100$ lifetime cigs) age $\geq$ 18 who were current smokers (smoking "everyday" or "some days") or former smokers (quit in the past 5 years) at the time of survey.

Young adult (18-30 years) current smokers who smoke every day (daily smokers) or some days (nondaily smokers).

Black adult ( $\geq 18$ years) "light smokers" ( $\leq 10$ CPD) for $\geq 2$ years who smoked on $\geq 25$ days in the
None

Middle school

(grades 6 to 8) and high school (grades 9 to 12)

Age 40-79 living in U.S. southern states

\section{Female prisoners}

None

(

None

Young adults age 18-30

Black light smokers $(\leq 10 \mathrm{CPD})$ 
Table 3 Study, Data Set, and Sample Characteristics (Continued)

\begin{tabular}{|c|c|c|c|c|}
\hline $\begin{array}{l}\text { First Author, } \\
\text { Year National } \\
\text { survey name } \\
\text { Quality rating }\end{array}$ & $\begin{array}{l}\text { Location; Funding; Type of } \\
\text { study }\end{array}$ & $\begin{array}{l}\text { Sampling / recruitment strategy; } \\
\text { Data collection period }\end{array}$ & $\begin{array}{l}\text { Brief summary of inclusion } \\
\text { criteria (including definition of } \\
\text { "smoker") }\end{array}$ & $\begin{array}{l}\text { Special } \\
\text { population }\end{array}$ \\
\hline Good & & population; NR & $\begin{array}{l}\text { month prior to enrollment and } \\
\text { were interested in quitting. }\end{array}$ & \\
\hline
\end{tabular}

$\begin{array}{ll}\text { Foulds et al., } & \text { New Jersey; } \\ 2006[35] & \text { Govt \& foundation; } \\ \text { None } & \text { Prospective cohort }\end{array}$

Good

\begin{tabular}{|c|c|}
\hline $\begin{array}{l}\text { Fu et al., } 2008 \\
\text { [36] } \\
\text { None } \\
\text { Good }\end{array}$ & $\begin{array}{l}5 \text { VA centers in U.S.; } \\
\text { Govt; } \\
\text { Prospective cohort }\end{array}$ \\
\hline $\begin{array}{l}\text { Gandhi et al., } \\
2009 \text { [37] } \\
\text { None } \\
\text { Fair }\end{array}$ & $\begin{array}{l}\text { New Jersey; } \\
\text { Govt \& foundation; } \\
\text { Retrospective cohort }\end{array}$ \\
\hline $\begin{array}{l}\text { Gubner et al., } \\
2018 \text { [38] } \\
\text { None } \\
\text { Good }\end{array}$ & $\begin{array}{l}\text { National (USA); } \\
\text { National Institute on Drug Abuse } \\
\text { (National Institutes of Health), } \\
\text { Food and Drug Administration } \\
\text { Center for Tobacco Products; } \\
\text { Cross-sectional }\end{array}$ \\
\hline
\end{tabular}

$\begin{array}{ll}\text { Gundersen } & \text { National; } \\ \text { et al., 2009 } & \text { NR; } \\ \text { [39] } & \text { Cross-sectional } \\ \text { NHIS-CCS } & \\ \text { Good } & \end{array}$

Hyland \& $\quad 2$ sites in each of: New Jersey,

Rivard, 2010; California, New Mexico, New York, Hyland et al., North Carolina, Canada; $2002[40,41] \quad$ Govt; None Prospective cohort

Good

\author{
Kahende et al., National; \\ 2011 [42] NR; \\ TUS-CPS Cross-sectional \\ Fair \\ Kasza et al., National; Foundation \& Govt; \\ 2014 [43] Prospective cohort \\ ITC-4 (U.S. data \\ only) \\ Fair
}

Keeler et al.,

2017 [44]

TUS-CPS

Fair

National (USA);

Tobacco Related Disease Research

$$
\text { Program; }
$$

Cross-sectional
Convenience sample of patients attempting to quit at a specialist tobacco dependence treatment outpatient clinic; 2001-2006

Participants recruited from 5 VA medical centers, identified by VA pharmacy databases; FebruaryOctober 2002

Consecutive patients at a specialist tobacco treatment outpatient clinic; January 2001-June 2005

Convenience sampling from each of Individuals with substance use 24 substance use disorder treatment disorders who self-reported as centers (in the National Institute on Drug Abuse Clinical Trials Network), with self-administered surveys conducted during on-site visits; April to December 2015

Administered in 1992, 2000, 2005, and 2010 as a supplement to the NHIS that assesses issues related to cancer-related behaviors, screening, and risk assessment, including tobacco use and control; 2005

COMMIT cessation trial; modified random-digit-dial method and geographic boundary screening used for the baseline prevalence survey to obtain representative samples of approximately $5400 \mathrm{HHs}$. Focused on communities with the highest prevalence of non-Whites; 19881993

Stratified multistage probability sample, civilian non-institutionalized U.S. population; 2003, 2006-2007

Random digit dialing to recruit adult smokers from the United States, Canada, the United Kingdom, and Australia. Eight waves have been completed between 2002 and 2011. Only U.S. data are included in this Review; 2002-2011

Stratified multistage probability

Adult recent active smokers age $\geq$ Smokers age 14-81 who, at their assessment, reported current smoking, specified a target quit date, and responded to the baseline night-smoking question.

Adult smokers age $\geq 19$ with a recent quit attempt that incorporated pharmacologic treatment.

Current smokers age 15-80 who set a quit date and attempted to quit smoking.

disorders who sef-

None, but included age $\geq 14$

VA patients

None, but included age $\geq 15$

Individuals with substance use disorders

Adult White, Black and Hispanic cig smokers ( $\geq 100$ lifetime cigs) age $\geq$

18 who ever attempted to quit smoking, do not currently use other tobacco products, and were current smokers (currently smoking "everyday" or "some days") or former smokers (currently smoke "not at all").

Adult current smokers age 25-64 who reported whether their current brand was mentholated or not in 1988, and had a known smoking status in 1993

Adults age $\geq 18$ who smoked cigs during the past year.

Adult smokers ( $\geq 100$ lifetime cigs and smoked $\geq$ once in past 30 days).

None ample, civilian non-institutionalized U.S. population; 2006 to 2007 and 2010 to 2011
None

None

None

None
18 , defined as current smokers or former smokers who quit less than 12 months ago; current smokers defined as smoking 100 cigarettes in their lifetime and currently smoking every day (daily smokers) or some days (someday smokers); former smokers defined as 
Table 3 Study, Data Set, and Sample Characteristics (Continued)

\begin{tabular}{|c|c|c|c|c|}
\hline $\begin{array}{l}\text { First Author, } \\
\text { Year National } \\
\text { survey name }\end{array}$ & $\begin{array}{l}\text { Location; Funding; Type of } \\
\text { study }\end{array}$ & $\begin{array}{l}\text { Sampling / recruitment strategy; } \\
\text { Data collection period }\end{array}$ & $\begin{array}{l}\text { Brief summary of inclusion } \\
\text { criteria (including definition of } \\
\text { "smoker") }\end{array}$ & $\begin{array}{l}\text { Special } \\
\text { population }\end{array}$ \\
\hline
\end{tabular}

Quality rating

individuals who smoked 100 cigarettes in their lifetime but currently do not smoke
Keeler et al., National (USA);

2018 [45]

TUS-CPS

Fair
Program;

Cross-sectional

$\begin{array}{ll}\text { Levy et al., } & \text { National; } \\ \text { 2011 [46] } & \text { Foundation; } \\ \text { TUS-CPS } & \text { Cross-sectional } \\ \text { Good } & \\ \text { Lewis et al., } & \text { National; } \\ \text { 2014 [47] } & \text { Govt; } \\ \text { None } & \text { Prospective cohort }\end{array}$

Muench and

Juliano, 2017

[48]

None

Good

Muscat et al 2002 [49]

None

Fair

$$
\text { Govt; }
$$

Prospective cohort University; study Pennsylvania; Govt;
Stratified multistage probability U.S. population; May/August 2006 to January 2007, and May/August 2010 to January 2011
Adult recent active smokers age $\geq$ 18 , to include current and former smokers who quit less than 12 months ago; current smokers, defined as having smoked 100 cigarettes in their lifetime and were currently smoking cigarettes every day or some days; former smokers defined as having smoked 100 cigarettes in their lifetime who currently did not smoke.

Stratified multistage probability sample, civilian non-institutionalized U.S. population; 2003, 2006-2007

Nielsen Homescan Panel which provides a record of consumerpackaged goods purchased by a large panel of nationally representative U.S. HHs;

January 2004-December 2009

Sample was recruited through flyers, word of mouth, and online advertisements, and participants were screened for eligibility by phone; NR

United States Department of Health and Human Services, National Institutes of Health, National Institute on Drug Abuse, and the College of Arts and Sciences at American Laboratory-based smoking-choice

New York, District of Columbia

Nonnemaker 7 communities in 5 states; et al., 2012 Govt;

[50]

None Prospective cohort

Good
Newly diagnosed cancer patients were identified from thoracic and other surgery schedules. Nonsurgical patients recruited from oncology wards. Controls were selected randomly from general hospital admitting rosters; 19811999 Tobacco Use Reduction Study (ALLTURS): School-based survey of middle and high school youth conducted in three waves in 83 schools in 7 communities in 5 states, initially selected for a quasi-experiment that included matched communities; 2000-2002

Kick it at Swope trial (KIS), inner-city health center mostly serving a lowincome Black population. Patients were invited to participate in a study on smoking among inner-city residents, not associated with a cessation program; August 2000-
American Legacy Longitudinal
Adults age $\geq 18$ who smoked $\geq 100$ lifetime cigs and were currently smoking or quit between 3 months and 5 years prior to the interview.

Cig purchasers (made $\geq 1 \mathrm{cig}$ purchase in 2004 and in 2005 or later and purchased $\geq 20$ packs between 2004 and 2009) who resided in 1 of the top 75 Designated Market Areas in order to track anti-smoking advertising. Homeowners were age $\geq 18$.

Adults age $\geq 18$ who smoked $a \geq 10$ None CPD for at least the past year, and with no intention or current attempt of quitting.

Black or White current smokers $(\geq 1$ CPD for the past year) and former smokers (current smokers at one time but did not smoke $\geq 1$ CPD for the preceding year).

Youth age $<18$ years who initiated smoking after baseline and before wave 3 and completed all 3 annual waves of the study.

Adult current smokers ( $\geq 10$ CPD) age $\geq 18$ who were Black, spoke English, had a home address with a working telephone, and were interested in quitting in the next 30 days.
Subsamples of African-American and White respondents, respectively.
None

None

$\begin{array}{ll}2003[51] & \text { Govt; } \\ \text { None } & \text { Prospective cohort }\end{array}$


Table 3 Study, Data Set, and Sample Characteristics (Continued)

\begin{tabular}{|c|c|c|c|c|}
\hline $\begin{array}{l}\text { First Author, } \\
\text { Year National } \\
\text { survey name }\end{array}$ & $\begin{array}{l}\text { Location; Funding; Type of } \\
\text { study }\end{array}$ & $\begin{array}{l}\text { Sampling / recruitment strategy; } \\
\text { Data collection period }\end{array}$ & $\begin{array}{l}\text { Brief summary of inclusion } \\
\text { criteria (including definition of } \\
\text { "smoker") }\end{array}$ & $\begin{array}{l}\text { Special } \\
\text { population }\end{array}$ \\
\hline
\end{tabular}

Quality rating

Okuyemi et al., Kansas;

2007 [52] Govt;

NoneGood Prospective cohort

Park, 2017 [53] National (USA);

NATS NR;

Good Cross-sectional

Pletcher et al., A major city in each of: Alabama, 2006 [54]

None Illinois, Minnesota, California;

Good Govt;

Prospective cohort

Rath et al National:

LYAC Prospective cohort

Fair

$\begin{array}{ll}\text { Reitzel, 2011a } & \text { Texas; } \\ \text { [56] } & \text { Govt; } \\ \text { None } & \text { Prospective cohort }\end{array}$

Good

$\begin{array}{ll}\text { Reitzel, 2011b } & \text { Texas; } \\ \text { [57] } & \text { Govt; } \\ \text { None } & \text { Prospective cohort } \\ \text { Good } & \\ \text { Reitzel, 2011c; } & \text { Texas; } \\ \text { Reitzel et al., } & \text { Govt; } \\ 2011[58,59] & \text { Prospective cohort } \\ \text { None } & \end{array}$

Good
2015 [55] Govt;

November 2000.

Kick it at Swope trial (KIS), inner-city health center mostly serving a lowincome Black population. Patients were invited to participate in a study on smoking among inner-city residents, not associated with a cessation program; March 2003-June 2004

Stratified, national, landline and cell phone survey of noninstitutionalized adults age $\geq 18$ across the 50 states and the District of Columbia; NATS 2012-2013 used a dual frame random digit dialing sample, drawn from landline and cell phone frames; October 2012 to July 2013

Coronary Artery Risk Development in Young Adults Study (CARDIA), population-based observational study of men and women age 1830 at baseline with follow-up data through year 19. Selected for equal representation in subgroups of race, gender, education, and age, recruited across 4 U.S. study sites; 1985-2000

Reitzel et al., Texas; 2013 [60] Govt;
Black adult ( $\geq 18$ years) light smokers ( $\leq 10$ CPD for $\geq 6$ months and smoking on $\geq 25$ of last 30 days) who were interested in setting a quit date within 14 days.

Adult current smokers age $\geq 18$, defined as having smoked least 100 cigarettes in their lifetime and currently smoked cigarettes every day or some days.

Black light smokers $(<10$ CPD) None

Young adult (18-30 years) Black or European-American current smokers.

Young adults age 18-30 at baseline
GfK's KnowledgePanel - an online panel of adults age 18 or older that covers both the online and offline populations in the U.S. Recruited via address-based sampling, a probability-based sampling method that provides statistically valid representation of the U.S. population, including cell-phone only households. Black and Hispanic young adults were oversampled; 2011-2012

Project BREAK FREE, recruited from within the Houston metro area through local print and radio advertisements; 2005-2007

Project CARE recruited from within the Houston metro area through local print and radio advertisements; 2005-2007

Project MOM, recruited from within Houston metropolitan area through a local health care system and via newspaper, radio, bus, and clinic advertisements; 2005-2007

Adults age 18-34 who completed the first 3 surveys and either remained current smokers across all 3 time points or initiated cig smoking at Time 2 and remained cig smokers at Time 3. Current smokers used $\geq 1$ cigs in the past 30 days.

Adult Blacks who smoked $\geq 5$ CPD for $\geq 12$ months, had eCO $\geq 8$ ppm, were willing to quit smoking in the next 2 weeks, had a working home telephone and a permanent address, and a 6th grade English literacy level.

Adult current smokers ( $\geq 5$ CPD for the past year) age $\geq 21$.

Adult women in week 30-33 of pregnancy at time of enrollment. Smokers ( $\geq 1$ CPD on average for the year) stopped smoking either during their pregnancy or within 2 months prior to becoming pregnant and wanted to remain quit postpartum. Women reporting a high-risk pregnancy were excluded.

Adult smokers age 18-65 ( $\geq 5$ CPD None for $\geq 12$ months) who had a working

Young adults

Blacks

Pregnant women
Longitudinal study among community smokers; 2006-2007 
Table 3 Study, Data Set, and Sample Characteristics (Continued)

\begin{tabular}{lllll}
\hline $\begin{array}{l}\text { First Author, } \\
\text { Year National } \\
\text { survey name } \\
\text { Quality rating }\end{array}$ & study & $\begin{array}{l}\text { Sampling / recruitment strategy; } \\
\text { Data collection period }\end{array}$ & $\begin{array}{l}\text { Brief summary of inclusion } \\
\text { criteria (including definition of } \\
\text { "smoker") }\end{array}$ & $\begin{array}{l}\text { Special } \\
\text { population }\end{array}$ \\
\hline
\end{tabular}

\begin{tabular}{ll}
\hline None & Prospective cohort \\
Fair &
\end{tabular}

Fair

$\begin{array}{ll}\text { Rojewski et al., } & \text { Connecticut; } \\ 2014 \text { [61] } & \text { Govt; } \\ \text { None } & \text { Prospective cohort } \\ \text { Good } & \\ \text { Sawdey et al., } & \text { National; } \\ \text { 2020 [62] } & \text { None; } \\ \text { NYTS } & \text { Cross-sectional } \\ \text { Good } & \end{array}$

Schneller et al., National;

2020; $\quad$ PATH contract mechanism;

Schneller, 2020 Cross-sectional

$[63,64]$

PATH

Fair

$\begin{array}{ll}\text { Stahre et al., } & \text { National; } \\ 2010 \text { [65] } & \text { Govt; } \\ \text { NHIS-CCS } & \text { Cross-sectional } \\ \text { Fair } & \end{array}$

$\begin{array}{ll}\begin{array}{l}\text { Steinberg } \\ \text { et al., 2011 }\end{array} & \begin{array}{l}\text { New Jersey; None; Retrospective } \\ \text { [66] }\end{array} \\ \begin{array}{l}\text { None } \\ \text { Good }\end{array} & \\ \text { Sulsky et al., } & \text { National; } \\ \text { 2014 [67] } & \text { Industry; } \\ \text { NHIS, TUS-CPS } & \text { Cross-sectional } \\ \text { Good } & \\ \text { Thihalolipavan } & \text { New York; } \\ \text { et al., 2014 } & \text { Govt; } \\ \text { [68] } & \text { Prospective cohort } \\ \text { None } & \\ \text { Poor } & \\ \text { Trinidad et al., } & \text { National; } \\ \text { 2010 [69] } & \text { Govt \& foundation; }\end{array}$

Media and provider referrals; 20052009

A nationally representative sample of students enrolled in grades 6 through 12. The sampling universe consists of public and private school students in the 50 states and the District of Columbia. Primary sampling units are selected with probability proportional to the student enrollment in the PSU but giving disproportionate weight to Black, Asian, and Hispanic students. All students present in a selected classroom on the day of the interview are selected for the study; 2011-2018

Nationally-representative survey of civilian, non-institutionalized US citizens, using addressed-based, probability sampling of households with adolescents. Data gathered in waves, beginning with Wave 1 (September 2013-December 2014) and having currently completed Wave 5 (2016-2017; data collection planned through 2024); 12 September 2013 to 14 December 2014 (Wave 1), 23 October 2014 to 30 October 2015 (Wave 2)

Administered in 1992, 2000, 2005, and 2010 as a supplement to the NHIS that assesses issues related to cancer-related behaviors, screening, and risk assessment, including tobacco use and control; 2005

Smokers intending to quit enrolled in a study for smoking cessation; 2006-2008

Stratified multistage probability sample, civilian non-institutionalized U.S. population; 2005, 2010 TUS-CPS; 2010-2011

New York City Nicotine Patch and Gum Program (NPGP), a nicotine replacement therapy giveaway administered to smokers who phoned a toll-free quitline; 2012

Stratified multistage probability sample, civilian non-institutionalized telephone number, permanent home address, and 6th grade literacy level. Willing to quit smoking in the next week and did not participate in a smoking cessation program in the last 3 months.

Weight-concerned smokers ( $>10$ CPD for $\geq 1$ year) with eCO $\geq 10$ ppm, $\geq 1$ prior quit attempt, and were enrolled in a cessation trial.

Youth (grades 6-12) current smokers that reported smoking a cigarette $\geq 1$ day

in the past 30 days

None

Middle and high school students (grades 6-12)

Current adult cigarette smokers that None have smoked at least 100 cigarettes in their lifetime and smoke every day or somedays

Adult current and former smokers age $\geq 18$ for whom menthol status was known.

Adult smokers age 16-78

None presenting for cessation treatment.

Adult current smokers $(\geq 100$

None etime cigs) and former smokers $(\geq 100$ lifetime cigs who quit $\geq 1$ year before survey).

Adult daily smokers in a nicotine replacement therapy giveaway.

None

Adult ever smokers age 20-65,

None 
Table 3 Study, Data Set, and Sample Characteristics (Continued)

\begin{tabular}{|c|c|c|c|c|}
\hline $\begin{array}{l}\text { First Author, } \\
\text { Year National } \\
\text { survey name } \\
\text { Quality rating }\end{array}$ & $\begin{array}{l}\text { Location; Funding; Type of } \\
\text { study }\end{array}$ & $\begin{array}{l}\text { Sampling / recruitment strategy; } \\
\text { Data collection period }\end{array}$ & $\begin{array}{l}\text { Brief summary of inclusion } \\
\text { criteria (including definition of } \\
\text { "smoker") }\end{array}$ & $\begin{array}{l}\text { Special } \\
\text { population }\end{array}$ \\
\hline $\begin{array}{l}\text { TUS-CPS } \\
\text { Good }\end{array}$ & Cross-sectional & U.S. population; 2003, 2006-2007 & $\begin{array}{l}\text { lifetime cigs and currently smoke } \\
\text { every day or some days) and former } \\
\text { smokers ( } \geq 100 \text { lifetime cigs and } \\
\text { currently smoke not at all). }\end{array}$ & \\
\hline $\begin{array}{l}\text { Webb Hooper } \\
\text { et al., } 2011 \\
{[70]} \\
\text { BRFSS } \\
\text { Good }\end{array}$ & $\begin{array}{l}\text { Florida; } \\
\text { Govt; } \\
\text { Cross-sectional }\end{array}$ & $\begin{array}{l}\text { BRFSS subsample from Florida; April } \\
2007 \text { - January } 2008\end{array}$ & $\begin{array}{l}\text { Adult smokers age } \geq 18 \text { ( } \geq 100 \\
\text { lifetime cigs and currently smoking } \\
\text { on some days). }\end{array}$ & None \\
\hline $\begin{array}{l}\text { Winhusen } \\
\text { et al., } 2013 \\
\text { [71] } \\
\text { None } \\
\text { Fair }\end{array}$ & $\begin{array}{l}\text { National; } \\
\text { Govt; } \\
\text { Prospective cohort }\end{array}$ & $\begin{array}{l}\text { Randomized trial examining } \\
\text { substance use disorder treatment } \\
\text { with smoking cessation treatment. } \\
\text { Participants recruited from one of } \\
12 \text { nationwide outpatient treatment } \\
\text { programs; Feb 2010-July } 2012\end{array}$ & $\begin{array}{l}\text { Adult current smokers ( } \geq 7 \text { CPD and } \\
\text { eCO } \geq 8 \text { ppm) enrolled in outpatient } \\
\text { treatment for cocaine or } \\
\text { methamphetamine addiction and } \\
\text { are interested in smoking. }\end{array}$ & $\begin{array}{l}\text { Cocaine- or } \\
\text { methamphetamine- } \\
\text { dependent } \\
\text { smokers. }\end{array}$ \\
\hline
\end{tabular}

Abbreviations: ALLTURS American Legacy Longitudinal Tobacco Use Reduction Study, BRFSS Behavioral Risk Factor Surveillance System, CARDIA Coronary Artery Risk Development in Young Adults Study, eCO exhaled carbon monoxide, COMMIT Community Intervention Trial for Smoking Cessation, CPD cigarettes per day, cigs cigarettes, Govt government, HH household, ITC-4 International Tobacco Control Four Country Survey (U.S. data only), KIS-III Kick it at Swope III Trial, LYAC Legacy Young Adult Cohort, NATS National Adult Tobacco Survey, NHIS National Health Interview Survey, NHIS-CCS National Health Interview Survey Cancer Control Supplement, NPGP New York City Nicotine Patch and Gum Program, NR not reported, NYTS National Youth Tobacco Survey, ppm parts per million, SCCS Southern Community Cohort Study, TUS-CPS Tobacco Use Supplement to the Current Population Survey, VA Veterans Health Administration

Table 3. The definitions of the specific outcome measures for smoking cessation applied across the adjusted studies are presented in SUPPLEMENTAL SECTION 3: Outcome Measures for Smoking Cessation across Adjusted Studies.
Table 4 contains a summary of the identified published assessments of the psychometric foundations for the smoking cessation measures. Empirical data regarding reliability or validity qualified four of the five smoking cessation measures (duration of abstinence, quit

Table 4 Overview of Psychometric Findings for Measures of Smoking Cessation

\begin{tabular}{|c|c|c|c|c|c|c|c|c|c|c|}
\hline \multirow[b]{3}{*}{ Scale or Measure } & \multicolumn{3}{|c|}{$\begin{array}{l}\text { Statistical reliability } \\
\text { indicator } \geq 0.70 ?\end{array}$} & \multirow{2}{*}{\multicolumn{3}{|c|}{$\begin{array}{l}\text { Statistical Validity Indicator? } \\
\text { [Criterion, Predictive, Convergent] }\end{array}$}} & \multicolumn{3}{|c|}{$\begin{array}{l}\text { External (Population) } \\
\text { Validity? }\end{array}$} & \multirow{3}{*}{$\begin{array}{l}\text { Overall } \\
\text { Psychometric } \\
\text { Rating }\end{array}$} \\
\hline & \multirow[t]{2}{*}{ Both Genders } & \multicolumn{2}{|c|}{ By Age } & & & & \multirow{2}{*}{$\begin{array}{l}\text { Both } \\
\text { Genders }\end{array}$} & \multicolumn{2}{|l|}{ By Age } & \\
\hline & & Adults & Youth & Behavioral & $\begin{array}{l}\text { Bio- } \\
\text { chemical }\end{array}$ & Cessation & & Adults & Youth & \\
\hline Duration of abstinence & Yes $[9,72,73]$ & $\mathrm{N} / \mathrm{A}$ & $\mathrm{N} / \mathrm{A}$ & Yes [74] & No & $\mathrm{N} / \mathrm{A}$ & Yes [9] & $\mathrm{N} / \mathrm{A}$ & N/A & $A$ \\
\hline \multicolumn{11}{|l|}{ Quit attempts } \\
\hline Any quit attempts & Yes $[75,76]$ & N/A & N/A & No & No & N/A & No & N/A & N/A & A \\
\hline $\begin{array}{l}\text { Number of quit } \\
\text { attempts per person }\end{array}$ & Yes $[73,76]$ & N/A & N/A & Yes [76] & No & N/A & No & N/A & N/A & \\
\hline \multicolumn{11}{|l|}{ Rate of abstinence/quitting } \\
\hline $\begin{array}{l}\text { Point/period prevalence } \\
\text { abstinence (PPA) }\end{array}$ & Yes [77-79] & $\mathrm{N} / \mathrm{A}$ & N/A & No & Yes [80-87] & N/A & No & N/A & N/A & A \\
\hline $\begin{array}{l}\text { Prolonged abstinence } \\
\text { (PA) }\end{array}$ & No & $\mathrm{N} / \mathrm{A}$ & N/A & Yes [85-89] & No & N/A & Yes & N/A & N/A & \\
\hline $\begin{array}{l}\text { Former smoker vs. } \\
\text { current smoker }\end{array}$ & No & N/A & N/A & No & No & N/A & No & N/A & N/A & \\
\hline $\begin{array}{l}\text { Menthol cigarette use } \\
\text { prior to quitting }\end{array}$ & No & N/A & N/A & No & No & N/A & No & N/A & N/A & \\
\hline $\begin{array}{l}\text { Change in smoking } \\
\text { quantity/frequency }\end{array}$ & $\begin{array}{l}\text { Yes [72-76, 79, } \\
86,90-95]\end{array}$ & N/A & N/A & $\begin{array}{l}\text { Yes }[74,79,80 \\
92,93,96]\end{array}$ & $\begin{array}{l}\text { Yes }[79,80, \\
93,96]\end{array}$ & N/A & $\begin{array}{l}\text { Yes [79, } \\
80]\end{array}$ & N/A & N/A & A \\
\hline Return to smoking/relapse & Yes [73] & N/A & $\mathrm{N} / \mathrm{A}$ & No & No & N/A & No & N/A & $\mathrm{N} / \mathrm{A}$ & । \\
\hline
\end{tabular}


Table 5 Summary of Evidence Related to Duration of Abstinence

\begin{tabular}{|c|c|c|c|}
\hline Study & $\begin{array}{l}\text { Sampling / Recruitment } \\
\text { Strategy }^{\mathrm{a}} \text {, Data Collection Period }\end{array}$ & Study Findings & $\begin{array}{l}\text { Study } \\
\text { Quality }\end{array}$ \\
\hline \multicolumn{4}{|c|}{ Decreased Duration of Abstinence with Menthol Cigarette Use } \\
\hline $\begin{array}{l}\text { Levy et al., } \\
2011 \text { [46] }\end{array}$ & TUS-CPS, 2003,2006/2007 & $\begin{array}{l}\text { Menthol cigarette use was associated with significantly lower odds of being a } \\
\text { "recent" quitter (those who quit in the past year and had been abstinent for at least } \\
3 \text { months; AOR }=0.97,95 \% \mathrm{Cl}: 0.96 \text { to } 0.97 ; p<0.001 \text { ) and a "long-term" quitter (those } \\
\text { who quit in the past } 5 \text { years and had been abstinent for at least } 3 \text { months; AOR }= \\
0.94 ; 95 \% \mathrm{Cl}: 0.94 \text { to } 0.94 ; p<0.001 \text { ), compared with use of non-menthol cigarettes. } \\
\text { Further controlling for nicotine dependence resulted in nearly identical odds ratios } \\
\text { for being a "recent" quitter (AOR }=0.97,95 \% \mathrm{Cl}: 0.96 \text { to } 0.97 ; p<0.001 \text { ) and a "long- } \\
\text { term" quitter (AOR }=0.95 ; 95 \% \mathrm{Cl}: 0.95 \text { to } 0.95 ; p<0.001 \text { ). A third adjusted model } \\
\text { detected similar odds ratios for "recent" quitters (AOR }=0.92,95 \% \mathrm{Cl}: 0.91 \text { to } 0.92 \text {; } \\
p<0.001 \text { ) and "long-term" quitters (AOR }=0.95 ; 95 \% \mathrm{Cl}: 0.95 \text { to } 0.95 ; p<0.001 \text { ). }\end{array}$ & Good \\
\hline \multicolumn{4}{|c|}{ Results of Mixed Significance for Duration of Abstinence } \\
\hline $\begin{array}{l}\text { Cubbin } \\
\text { et al., } 2010 \\
\text { [29] }\end{array}$ & NHIS-CCS; 2005 & $\begin{array}{l}\text { Increase in Duration of Abstinence with Menthol Cigarette Use } \\
\text { Among the six gender-race/ethnicity interactions, White female former menthol } \\
\text { smokers reported significantly longer abstinence than White female former non- } \\
\text { menthol smokers (14.8 years vs. } 12.5 \text { years, respectively; } p<0.01 \text { ). } \\
\text { No Difference } \\
\text { For the other interactions (White males, Black females, Black males, Hispanic females, } \\
\text { and Hispanic males), no difference was found. }\end{array}$ & Good \\
\hline
\end{tabular}

a Details of sampling and recruitment strategies for the data sources can be found in Table 3: Study, Data Set, and Sample Characteristics

attempts, rate of abstinence/quitting, change in smoking quantity/frequency) as "acceptable".

\section{Synthesis of the best available evidence}

Summaries of the best available evidence - controlling for age, race/ethnicity, and gender - are presented by outcome measure below. Outcome measures are presented with a corresponding overview table for each measure in the following order: duration of abstinence; quit attempts; rate of abstinence/quitting; change in smoking quantity/frequency; and return to smoking/relapse. Where two references reported the same data, the most recent publication was used as the data source. The complete data extraction for all included adjusted studies can be found in SUPPLEMENTAL SECTION 4: Evidence Table, Modeled / Adjusted Results.

\section{Duration of abstinence}

Two studies, presented in Table 5, reported duration of abstinence.

Levy at al [46]. reported significantly lower odds of being a "recent" and "long-term" quitter for menthol compared with non-menthol smoking, across all models (AORs ranged from 0.92 to 0.97 across models). Cubbin et al. [29] reported duration of abstinence for six gender-race/ethnicity interactions, yielding only one significant finding that suggested White female menthol smokers had been abstinent significantly longer than White female non-menthol smokers (14.8 years vs. 12.5 years; $p<0.01)$. Given the limited number of studies and the inconsistent findings reported for this measure, an association between menthol cigarette use and duration of abstinence is unclear and undefined in the evidence base.

\section{Quit attempts (any quit attempts; number of quit attempts per person)}

Fifteen studies (from 16 references), as presented in Table 6, reported measures of quit attempts.

Kahende at al [42]. reported White menthol smokers had significantly lower odds than White non-menthol smokers of having made a past-year quit attempt $(\mathrm{AOR}=0.91,95 \% \mathrm{CI}: 0.84$ to $0.99 ; p<0.05)$.

Ten studies (from 11 references) found no difference between menthol and non-menthol smokers in terms of having made at least one quit attempt (within various timeframes), across all models and subgroup analyses/ stratifications performed $[25,29,33,41,43,53-55,63$, 64, 70]. In addition, Stahre et al. [65] found no significant difference in the odds of using any type of quit aid between menthol and non-menthol current smokers, nor menthol and non-menthol former smokers.

Three studies reported mixed findings. Levy et al. [46] reported that menthol cigarette smokers had significantly higher odds of past-year quit attempts compared to non-menthol users $(\mathrm{AOR}=1.03,95 \% \mathrm{CI}$ : 1.02 to 1.03 ; $p<0.001)$; this result remained unchanged when adding nicotine dependence to the model. However, a third model (adjusting for additional, unspecified covariates) reported significantly lower odds of past year quit attempts among menthol cigarette smokers (AOR $=0.98$, 95\% CI: 0.98 to 0.98). In Keeler et al. [44], the overall odds of past-year quit attempts between menthol and non-menthol smokers were no different. Both the 2017 and 2018 studies by Keeler at al [44, 45]. found that, 
Table 6 Summary of Evidence Related to Quit Attempts

\begin{tabular}{llll}
\hline Study & $\begin{array}{l}\text { Sampling / Recruitment Strategy }{ }^{\mathrm{a}} \text {, Data } \\
\text { Collection Period }\end{array}$ & Study Findings & $\begin{array}{l}\text { Study } \\
\text { Quality }\end{array}$ \\
\hline
\end{tabular}

Decreased Quit Attempts with Menthol

Kahende et al., $\quad$ TUS-CPS; 2003, 2006/2007 2011 [42]

No Difference in Quits Attempt with Menthol Cigarette Use

\author{
Kasza et al., $2014 \quad$ ITC-4, 2002-2011 \\ [43]
}

Park, 2017 [53] Dual frame random-digit dialing sample; October 2012 to July 2013

Rath et al., $2015 \quad$ LYAC; 2011-2012

[55]

Webb Hooper

et al., 2011 [70]

BRFSS subsample from Florida; April 2007 January 2008

Alexander et al., TUS-CPS, 2006-2007

2010 [25]

Cubbin et al., 2010 NHIS-CCS, 2005

[29]

Hyland \& Rivard, C COMMIT cessation trial; 1988-1993

2010 [41]

Stahre et al., 2010 NHIS-CCS, 2005

[65]

Fagan et al., 2007 TUS-CPS; young adults age 18 to 30; 2003

[33]

Pletcher et al., 2006 [54]
CARDIA; men and women age $18-30$ at baseline; 1985-2000
Schneller et al., 2020 [63];

Schneller, 2020

[64]
White menthol smokers had significantly lower odds of having made a quit attempt in the past year ( $A O R=0.91,95 \% \mathrm{Cl}: 0.84$ to $0.99 ; p<0.05)$.

No difference between smokers who switched from menthol to non-menthol cigarettes compared to smokers who continued smoking menthol cigarettes in quit attempts during (AOR $=1.09$, 95\% Cl: 0.78 to 1.52 ) or after ( $A O R=1.03,95 \%$ Cl: 0.66 to 1.60 ) the switch. Switchers from non-menthol to menthol cigarettes were also no different from smokers who attempted to quit but continued with non-menthol cigarettes during $(A O R=1.12,95 \% \mathrm{Cl}: 0.80$ to 1.57 ) or after ( $\mathrm{AOR}=0.91,95 \% \mathrm{Cl}: 0.57$ to 1.44$)$ the switch.

No difference between menthol and non-menthol smokers in the likelihood of a past-year quit attempt (AOR $=1.19,95 \% \mathrm{Cl}: 0.97$ to1.46; $p=0.92$ ).

No difference between menthol and non-menthol smokers in ever Fair having made a quit attempt (AOR $=0.84,95 \% \mathrm{Cl}: 0.43$ to 1.63 ) or having made a quit attempt in the past 6 months $(A O R=0.62$, 95\% Cl: 0.30 to 1.27$)$.

No difference between menthol and non-menthol smokers in past Good year quit attempts ( $\mathrm{AOR}=0.96,95 \% \mathrm{Cl}: 0.81$ to 1.15 ).

No difference between menthol and non-menthol smokers in the Good odds of making a quit attempt ( $\mathrm{AOR}=0.98,95 \% \mathrm{Cl}: 0.83$ to 1.15).

No differences between menthol and non-menthol smokers across Good all six gender-race/ethnicity interactions in predicted past year quit attempts.

No differences between menthol and non-menthol smokers in the Good odds of having made a quit attempt (AOR $=0.91,95 \% \mathrm{Cl}: 0.72$ to 1.15); similarly, no differences were found when analyzing subgroups of Black and White smokers.

No differences between menthol and non-menthol current smokers ( $\mathrm{AOR}=1.05,95 \% \mathrm{Cl}: 0.80$ to 1.36 ) or former smokers $(A O R=1.29,95 \% \mathrm{Cl}: 0.74$ to 2.26$)$ in using any type of quit aid.

No differences between menthol and non-menthol current smokers ( $A O R=1.00,95 \% \mathrm{Cl}: 0.89$ to 1.16$)$, current daily smokers $(\mathrm{AOR}=1.00,95 \% \mathrm{Cl}: 0.85$ to 1.18$)$, or non-daily smokers (AOR = $0.93,95 \% \mathrm{Cl}: 0.62$ to 1.41 ) in the odds of past-year quit attempts. Moreover, no difference was found in the odds of past-year quit attempts between menthol and non-menthol non-daily smokers who reported an intention to quit ( $\mathrm{AOR}=1.35,95 \% \mathrm{Cl}: 0.60$ to 3.03).

Adjusting for various factors in 3 models, results across all models were similar in direction, significance, and magnitude and found no difference between menthol and non-menthol smokers in the likelihood of having made a quit attempt in the period preceding each interview ( $A O R=0.77,95 \% \mathrm{Cl}$ : 0.56 to 1.06 ; most restrictive model, adjusting for age, race/ethnicity, gender, social factors, and (PD at baseline)

No significant difference in the adjusted risk of menthol users reporting a past 12 month quit attempt compared to non-menthol users (RRR $=1.00,95 \% \mathrm{Cl}: 0.89-1.13, p=N S)$. 2014 (Wave 1), 23 October 2014 to 30 October 2015 (Wave 2)

Results of Mixed Significance in Quit Attempts

Keeler et al., 2018 Probability sampling of stratified clusters of U.S. [45] households; May/August 2006 to January 2007, and May/ August 2010 to January 2011 ncrease with Menthol Cigarette Use Black menthol, compared to non-menthol, smokers were significantly more likely to report any past-year quit attempts ( $A O R=$ $1.39,95 \%$ Cl: 1.16 to $1.67 ; p<0.001)$. No difference 
Table 6 Summary of Evidence Related to Quit Attempts (Continued)

\begin{tabular}{|c|c|c|c|}
\hline Study & $\begin{array}{l}\text { Sampling / Recruitment Strategy }{ }^{a} \text {, Data } \\
\text { Collection Period }\end{array}$ & Study Findings & $\begin{array}{l}\text { Study } \\
\text { Quality }\end{array}$ \\
\hline & & $\begin{array}{l}\text { No difference between White menthol and non-menthol smokers } \\
\text { in the odds of past-year quit attempts (AOR }=0.95,95 \% \mathrm{Cl}: 0.89 \text { to } \\
1.01 ; \mathrm{p}=\mathrm{NS}) \text {. }\end{array}$ & \\
\hline $\begin{array}{l}\text { Keeler et al., } 2017 \\
\text { [44] }\end{array}$ & $\begin{array}{l}\text { Probability sampling of stratified clusters of U.S. } \\
\text { households; } \\
2006 \text { to } 2007 \text { and } 2010 \text { to } 2011\end{array}$ & $\begin{array}{l}\text { Increase with Menthol Cigarette Use } \\
\text { Black menthol smokers were significantly more likely to report } \\
\text { past-year quit attempts than non-menthol smokers ( } \mathrm{AOR}=1.37 \text {, } \\
95 \% \text { Cl: } 1.16 \text { to } 1.61 ; p=0.0002 \text { ). } \\
\text { No difference } \\
\text { No difference between menthol and non-menthol smokers in } \\
\text { past-year quit attempts (AOR }=0.9995 \% \mathrm{Cl}: 0.94 \text { to } 1.04 ; p= \\
0.6690) \text {. } \\
\text { Similarly, no difference in the odds of past-year quit attempts be- } \\
\text { tween: White menthol and non-menthol smokers (AOR }=0.97,95 \% \\
\text { Cl: } 0.91 \text { to } 1.02 ; p=0.2450 \text { ); Asian menthol and non-menthol } \\
\text { smokers (AOR }=0.91,95 \% \mathrm{Cl}: 0.62 \text { to } 1.34 ; p=0.6470 \text { ); or Hispanic } \\
\text { menthol and non-menthol smokers (AOR }=1.09,95 \% \text { Cl: } 0.91 \text { to } \\
\text { 1.30; } p=0.3540 \text { ). }\end{array}$ & Fair \\
\hline $\begin{array}{l}\text { Levy et al., } 2011 \\
\text { [46] }\end{array}$ & $\begin{array}{l}\text { TUS-CPS; } \\
\text { current smokers and former smokers who quit } \\
\text { between } 3 \text { months and } 5 \text { years prior to the } \\
\text { survey interview; } \\
2003,2006 / 2007\end{array}$ & $\begin{array}{l}\text { Increase with Menthol Cigarette Use } \\
\text { Menthol, versus non-menthol, smokers who were smoking } 1 \text { year } \\
\text { prior to the interview had a significantly higher likelihood of past } \\
\text { year quit attempts (AOR }=1.03,95 \% \mathrm{Cl}: 1.02 \text { to } 1.03 ; p<0.001 \text { ). Fur- } \\
\text { ther controlling for nicotine dependence resulted in a nearly iden- } \\
\text { tical and significantly higher likelihood of a past year quit attempt } \\
\text { for menthol, versus non-menthol, smokers who were smoking } 1 \\
\text { year prior to the interview (AOR }=1.02,95 \% \mathrm{Cl}: 1.02 \text { to } 1.03 ; p< \\
0.001 \text { ). } \\
\text { Decrease with Menthol Cigarette Use } \\
\text { A third adjusted model reported significantly lower odds of past- } \\
\text { year quit attempts for menthol, versus non-menthol, smokers } \\
\text { (AOR }=0.98,95 \% \text { Cl: } 0.98 \text { to } 0.98 \text { ). }\end{array}$ & Good \\
\hline
\end{tabular}

${ }^{a}$ Details of sampling and recruitment strategies for the data sources can be found in Table 3: Study, Data Set, and Sample Characteristics

among black smokers, menthol users were significantly more likely to report past-year quit attempts (2018: $\mathrm{AOR}=1.39,95 \%$ CI: 1.16 to $1.67 ; p<0.001 ; 2017$ : $\mathrm{AOR}=1.37,95 \% \mathrm{CI}: 1.16$ to $1.61 ; p=0.0002)$; no such differences were reported for other racial/ethnic subgroups. The majority of the results from these 14 studies reported no differences between menthol and nonmenthol smoking in terms of quit attempts.

\section{Rate of abstinence/quitting}

Twenty-nine studies (from 33 references), presented below in Table 7 , reported on rate of abstinence/quitting outcomes.

Four studies found that menthol smokers had significantly lower odds of quitting than non-menthol smokers; two studies reported 7-day PPA (between weeks 14 and 26 [61]; and at the previous 7 days and at week 7 [34]), while two studies examined cessation at different time points ( 1 year abstinence from purchasing a pack of cigarettes [47]; and abstinence at 3 to 6 week follow-up [68]).

Sixteen studies (from 18 references) found no difference in the rate of abstinence between menthol and non-menthol smokers, both overall and within subgroup analyses, in terms of: 7-day PPA in six studies [28, 35,
36, 52, 66, 71]; 30-day PPA in one study [30]; quit rates from baseline to follow-up in three studies from four references [40, 41, 50,54]; cessation of greater than 3 months in two studies [44, 45]; PA in two studies [56, 57]; successful cessation between two survey waves in one study from two references [63, 64]; and past-year abstinence in one study [49].

Nine studies (from 11 references), reported mixed significance [27, 31, 32, 37, 39, 51, 58-60, 67, 69]. Using NHIS data, Sulsky et al. [67] found that White menthol and non-menthol regular and daily smokers were no different in odds of past-year abstinence; similar results were observed in Black menthol and non-menthol daily smokers. Using TUS-CPS data, the authors found no significant difference in one- to three-year abstinence between White menthol and non-menthol smokers (both regular and daily). For other race/ethnicities, no difference was detected between menthol and nonmenthol use in terms of abstinence among regular and daily smokers. However, for Black daily $(\mathrm{AOR}=0.89$, 95\% CI: 0.81 to 0.98 ) and regular $(\mathrm{AOR}=0.87,95 \% \mathrm{CI}$ : 0.80 to 0.95 ) smokers, menthol use was significantly associated with lower odds of abstinence.

Reitzel et al. [60] found that menthol and nonmenthol smokers were no different in terms of short- 
Table 7 Summary of Evidence Related to Rate of Abstinence/Quitting

\begin{tabular}{|c|c|}
\hline Study & $\begin{array}{l}\text { Sampling / Recruitment Strategy }{ }^{\mathrm{a}} \text {, Data Collection } \\
\text { Period }\end{array}$ \\
\hline \multicolumn{2}{|c|}{ Decreased Rate of Abstinence/Quitting with Menthol Cigarette Use } \\
\hline $\begin{array}{l}\text { Thihalolipavan } \\
\text { et al., } 2014 \text { [68] }\end{array}$ & $\begin{array}{l}\text { New York City Nicotine Patch and Gum Program; } \\
2012\end{array}$ \\
\hline $\begin{array}{l}\text { Lewis et al., } 2014 \\
\text { [47] }\end{array}$ & $\begin{array}{l}\text { Nielsen Homescan Panel; } \\
\text { January 2004-December } 2009\end{array}$ \\
\hline $\begin{array}{l}\text { Rojewski et al., } \\
2014 \text { [61] }\end{array}$ & $\begin{array}{l}\text { A trial of } 166 \text { weight-concerned smokers who smoked at } \\
\text { least } 10 \text { CPD for at least a year and had at least one prior } \\
\text { quit attempt; } \\
2005-2009\end{array}$ \\
\hline $\begin{array}{l}\text { Faseru et al., } 2013 \\
\text { [34] }\end{array}$ & $\begin{array}{l}\text { KIS-III trial; } \\
\text { community-based clinic sample serving a predominantly } \\
\text { Black population; } \\
\text { 2007-2010 }\end{array}$ \\
\hline
\end{tabular}

No Difference in Rate of Abstinence/Quitting with Menthol Cigarette Use

\author{
Keeler et al., 2018 Probability sample of U.S. households; \\ [45] personal and telephone interviews; \\ May/August 2006 to January 2007, and May/August 2010 \\ to January 2011
}

Keeler et al., 2017 Probability sample of U.S. households; personal and [44] telephone interviews, 2006 to 2007 and 2010 to 2011

Winhusen et al., 2013 [71]

D'Silva et al., 2012 ClearWay Minnesota phone line; [30] September 2009 - July 2011, 7-month post-registration follow-up survey March 2010-February 2011

Nonnemaker et al., 2012 [50]

ALLTURS;

Randomized trial of U.S. substance use outpatient treatment program participants receiving smoking cessation treatment; Feb 2010-July 2012

Reitzel, 2011a [56] Project BREAK FREE; Houston metro area; 2005-2007

$\begin{array}{cl}\text { Reitzel, 2011b [57] } & \text { Project CARE; } \\ & \text { Texas; }\end{array}$

2005-2007

Steinberg et al., Cessation study that enrolled 723 smokers age 16-78 2011 [66]
Study Findings

Study

Quality

Smoking menthol cigarettes was associated with a $10 \%$

Poor lower prevalence of quitting ( $\mathrm{PR}=0.90,95 \% \mathrm{Cl}: 0.83$ to 0.97) after 3 to 6 weeks.

Menthol smokers had a significantly lower likelihood of Fair quitting compared with non-menthol smokers ( $\mathrm{HR}=$ $0.79,95 \%$ Cl: 0.64 to 0.99 ).

Menthol smokers were significantly less likely to be abstinent; specifically, non-menthol smokers were 2.4 times more likely to report 7-day PPA Weeks 14 and 26 (Week 14: $\mathrm{AOR}=2.40,95 \%$ Cl: 1.04 to 5.55; Week 26 $\mathrm{AOR}=2.47,95 \% \mathrm{Cl}: 1.40$ to $5.90 ; p=0.04$ ).

Menthol cigarette use was associated with significantly lower odds of cotinine-verified 7-day PPA at the end of 7 weeks of treatment compared to non-menthol cigarette use; specifically, non-menthol, compared to menthol, smokers had $84 \%$ greater odds of 7-day PPA at week $7(\mathrm{AOR}=1.84,95 \% \mathrm{Cl}: 1.01$ to 3.36; $p<0.05)$.

No difference between Black menthol and non-menthol Fair smokers in the rate of successful cessation ( $\geq 3$ months $(A O R=1.01,95 \% \mathrm{Cl}: 0.70$ to $1.45 ; p=N S$ ). Similarly, no difference was found for the rate of successful cessation ( $\geq 3$ months) between White menthol and non-menthol smokers ( $\mathrm{AOR}=0.94,95 \% \mathrm{Cl}: 0.84$ to 1.07 ).

No difference between menthol and non-menthol smokers in the odds of cessation ( $\geq 3$ months ( $A O R=$ 0.92 95\% Cl: 0.83 to $1.03 ; p=0.1470$ ). Similarly, no difference for the odds of cessation in subgroup analyses of: Black menthol and non-menthol smokers ( $A O R=1.03$, 95\% Cl: 0.73 to $1.44 ; p=0.8630)$; White menthol and non-menthol smokers (AOR $=0.94,95 \% \mathrm{Cl}: 0.84$ to 1.06 ; $p=0.3190$ ); Asian menthol and non-menthol smokers ( $\mathrm{AOR}=0.98,95 \% \mathrm{Cl}: 0.44$ to $2.19 ; p=0.9540$ ); and Hispanic menthol and non-menthol smokers $(A O R=0.88$, $95 \%$ Cl: 0.60 to $1.28 ; p=0.4980$.

No difference in effect for smoking cessation (as measured by 7-day PPA at week 10) between menthol and non-menthol cigarette type among either the cocaine-dependent $(p=0.81$ ) or methamphetaminedependent $(p=0.9)$ participants.

No difference between menthol and non-menthol smokers in the odds of quitting (as assessed by 30-day PPA (AOR $=1.29,95 \%$ Cl: 0.77 to 2.15 ).

No difference between those who initiated smoking with menthol and non-menthol in quit rates (AOR = $1.18,95 \%$ Cl: 0.78 to 1.80 ; ref. $=$ NM).

No difference between menthol and non-menthol cigarette use in predicting prolonged abstinence from smoking among Black smokers in adjusted analyses $(\beta=.33, \mathrm{SE}=.32 ; \times 2=1.06 ; p=.30 ; n=457)$.

No difference between menthol and non-menthol cigarette use in predicting prolonged abstinence from smoking in adjusted analyses $(\beta=0.05, \mathrm{SE}=0.25 ; \times 2=$ $0.04 ; p=0.84$ ).

No difference between menthol and non-menthol smokers in the odds of abstinence (7-day PPA) at 6 months after target quit date (AOR $=1.02,95 \% \mathrm{Cl}: 0.66$ to 1.58$)$. 
Table 7 Summary of Evidence Related to Rate of Abstinence/Quitting (Continued)

\begin{tabular}{ll}
\hline Study & $\begin{array}{l}\text { Sampling / Recruitment Strategy } \\
\text {, }\end{array}$ \\
& Period \\
\hline Hyland et al., 2002 & COMMIT cessation trial; modified random-digit-dial \\
[40]; Hyland \& & method of approximately 5400 HHs with focus on com- \\
Rivard, 2010 [41] & $\begin{array}{l}\text { munities with the highest prevalence of non-Whites; } \\
1988-2001\end{array}$
\end{tabular}

\section{Study Findings}

No differences in quit rates between menthol and non-

menthol smokers who were smoking from 1988 to 2001 and had not attempted to quit (AOR $=0.84,95 \% \mathrm{Cl}: 0.61$ to 1.15$)$, who had attempted to quit $(\mathrm{AOR}=1.03,95 \% \mathrm{Cl}$ : 0.71 to 1.48), or among the corresponding White subsamples (no quit attempts: $\mathrm{AOR}=0.79,95 \% \mathrm{Cl}: 0.56$ to 1.11; quit attempts: $\mathrm{AOR}=0.96,95 \% \mathrm{Cl}: 0.65$ to 1.41 ). Also, no difference in quitting between menthol and non-menthol cigarette use in 1988 among: smokers in 1993 (AOR $=1.00,95 \% \mathrm{Cl}: 0.90$ to 1.11); White smokers $(\mathrm{AOR}=0.94,95 \% \mathrm{Cl}: 0.83$ to 1.05$)$; Black smokers $(\mathrm{AOR}=$ 1.04, $95 \% \mathrm{Cl}: 0.73$ to 1.47); and Hispanic smokers (AOR = $1.22,95 \%$ Cl: 0.80 to 1.87 ).
Cropsey et al., $\quad$ Female prison sample; 2009 [28] June 2004-June 2006

Fu et al., 2008 [36] VA medical center sample; February-October 2002

Okuyemi et al., 2007 [52]

KIS trial; cessation program of an inner-city health center mostly serving a low-income Black population; March 2003-June 2004

No differences between menthol and non-menthol smokers in smoking cessation (as evaluated by 7 -day PPA (Wald chi-square $=1.2 ; p=0.272$; and with interaction of race $X$ menthol: Wald chi-square $=0.1 ; p=$ 0.27).

No difference between menthol and non-menthol smokers in smoking abstinence (as assessed by selfreported 7-day PPA (AOR = 1.31, 95\% Cl: 0.95 to 1.82).

No difference was found for 7-day PPA at week $26(p=$ 0.93 ) between categorized age ( $<50$ versus $\geq 50$ years) and menthol status. Further, among the $<50$ years of age group, no difference between menthol and nonmenthol smokers in cessation rates $(\mathrm{AOR}=2.077,95 \% \mathrm{Cl}$ : 0.944 to $4.569 ; p=0.069$ ). Likewise, among those $\geq 50$ years, no difference between menthol and non-menthol cigarette use in abstinence (AOR $=1.676 ; 95 \% \mathrm{C} 1: 0.760$ to $3.698 ; p=0.221$ ).

Foulds et al., 2006 Convenience sample of patients attempting to quit at a [35] specialist tobacco dependence treatment outpatient clinic; 2001-2006

Pletcher et al., CARDIA;

2006 [54] men and women in the U.S. age 18-30 at baseline with follow-up data through year 19; 1985-2000

At the four-week follow up, was no difference between menthol and non-menthol smokers in 7-day PPA (AOR = $1.36,95 \%$ Cl: 1.0 to 1.86$)$.

No different between menthol and non-menthol smokers in quit rate (i.e., not currently smoking at any examination ( $\mathrm{AOR}=0.90,95 \% \mathrm{Cl}: 0.68$ to 1.19 ). There was also no difference in quitting between menthol and non-menthol smokers who tried to quit $(\mathrm{AOR}=1.00$, 95\% Cl: 0.71 to 1.42). In longitudinal analyses, no difference between menthol and non-menthol smokers in sustained smoking cessation ( $\mathrm{AOR}=0.71,95 \% \mathrm{Cl}: 0.49$ to $1.02 ; p=0.06)$.

Muscat et al., 2002 Newly diagnosed, non-surgical cancer patients; 1981-1999 [49]
Schneller et al., 2020 [63];

Schneller, 2020

[64]

PATH;

12 September 2013 to 14 December 2014 (Wave 1), 23 October 2014 to 30 October 2015 (Wave 2)
Results of Mixed Significance in Rate of Abstinence/Quitting

$\begin{array}{ll}\text { Sulsky et al., } 2014 & \text { NHIS; } \\ \text { [67] } & \text { 2005,2010; } \\ & \text { TUS-CPS; } \\ & \text { 2010/2011 }\end{array}$

In adjusted analyses, no difference was found between menthol and non-menthol cigarette use in continued smoking among Black participants ( $P O R=1.1,95 \% \mathrm{Cl}$ : 0.8 to 1.4 ) and White participants (POR $=1.1,95 \% \mathrm{Cl}: 1.0$ to 1.3).

No significant difference in the adjusted odds of menthol users reporting successful cessation at Wave 2 compared to non-menthol users, when adjusting for gender, age, race/ethnicity, education, and HSI $(A O R=$ 1.09, 95\% Cl: 0.88-1.37, $p=$ NS). In a similar model-replacing HSI (above) with CPD-the results were almost identically non-significant (RRR $=1.09,95 \% \mathrm{Cl}$ : 0.87-1.35, $p=\mathrm{NS}$ )

Decrease with Menthol Cigarette Use According to the TUS-CPS data, menthol cigarette use among Black regular and daily smokers was significantly lower for the adjusted odds of abstinence for $1-3$ years (regular smokers: $\mathrm{AOR}=0.87,95 \% \mathrm{Cl}: 0.80$ to 0.95 ; daily smokers: $A O R=0.89,95 \%$ Cl: 0.81 to 0.98$)$.

\section{Study} Quality

Good 
Table 7 Summary of Evidence Related to Rate of Abstinence/Quitting (Continued)

\begin{tabular}{|c|c|c|}
\hline Study & $\begin{array}{l}\text { Sampling / Recruitment Strategy }{ }^{\text {a }} \text {, Data Collection } \\
\text { Period }\end{array}$ & Study Findings \\
\hline
\end{tabular}

\section{No Difference}

According to the NHIS data, among White participants, there was no difference between menthol regular and daily smokers in the adjusted odds of past-year abstinence (regular smokers: $\mathrm{AOR}=1.06,95 \% \mathrm{Cl}: 0.95$ to 1.18 . daily smokers: $\mathrm{AOR}=1.04,95 \% \mathrm{Cl}: 0.82$ to 1.33 ). No difference between White menthol and nonmenthol regular and daily smokers in the adjusted odds of abstinence for 1-3 years (regular smokers: $A O R=0.97$, 95\% Cl: 0.94 to 1.00; daily smokers: $\mathrm{AOR}=0.98,95 \% \mathrm{Cl}$ : 0.95 to 1.01$)$.

For participants whose race/ethnicity was other than White or Black, no difference for abstinence for 1-3 years between menthol and non-menthol smokers (regular smokers: $\mathrm{AOR}=0.99,95 \% \mathrm{Cl}: 0.91$ to 1.08 ; daily smokers: $\mathrm{AOR}=1.00,95 \% \mathrm{Cl}: 0.92$ to 1.09$)$.

Reitzel et al., 2013 Texas;

[60] lung cancer case-control study; February 1996-July 2001

Blot et al., 2011 [27]

40-79year olds living in southern U.S. states; March 2002 - September 2009
Decrease with Menthol Cigarette Use

Menthol cigarette use was significantly associated with a lower probability of short-term continuous smoking abstinence among White participants $(\beta=-1.56, \mathrm{SE}=0.79$; $X 2=3.96 ; p=0.05$ ). Racially stratified analyses also found a significant association of menthol cigarette use with 7day PPA smoking abstinence through post-quit Week 3 among White participants $(\beta=-1.90, \mathrm{SE}=0.82 ; p=$ 0.02).

No difference

No significant effect of menthol cigarette use status on continuous short-term smoking abstinence $(\beta=-0.31$, $\mathrm{SE}=0.40 ; \times 2=0.60 ; p=0.44$ ).

Moreover, no difference between Black menthol, versus non-menthol, smokers for short-term continuous smoking abstinence $(\beta=0.54, \mathrm{SE}=0.55 ; \times 2=0.95 ; p=0.33)$; even after racially stratifying analyses, no difference between Black menthol and non-menthol smokers according to 7-day PPA ( $\beta=1.00, \mathrm{SE}=0.67 ; p=0.11)$.

Increase with Menthol Cigarette Use

Adjusting for age and other covariates, White menthol, versus non-menthol, cigarette smokers were more likely to have quit smoking prior to study enrollment $(\mathrm{AOR}=$ $1.55,95 \% \mathrm{Cl}: 1.41$ to 1.70 ).

No difference

No difference between Black menthol and non-menthol cigarette smokers in the likelihood of quitting smoking prior to study enrollment (AOR $=1.03,95 \% \mathrm{Cl}: 0.96$ to 1.11).

Adjusted odds of being a former smoker (menthol versus non-menthol) was measured across five sample restrictions: cigarette smokers and former smokers who quit in the past 5 years (restriction 1); cigarette smokers and former smokers who quit in the past 5 years who do not currently use other tobacco products (restriction 2); cigarette smokers and former smokers who quit in the past 5 years who have made a quit attempt (restriction 3); cigarette smokers and former smokers who quit in the past 5 years who have made a quit attempt and do not currently use other tobacco products (restriction 4); and past-year smokers (restriction 5, also adjusting for past-year cigarette tax increase).

Decrease with Menthol Cigarette Use

The odds of being a former smoker were significantly lower among menthol, versus non-menthol, smokers in the overall sample with the least restrictions (restriction 1; $\mathrm{AOR}=0.91,95 \% \mathrm{Cl}: 0.87$ to 0.96$)$. The same significant difference was consistently found across restrictions 2, 3, and 4 with AORs ranging from 0.90 to 0.92 .

Black menthol smokers were significantly less likely to 
Table 7 Summary of Evidence Related to Rate of Abstinence/Quitting (Continued)

\begin{tabular}{|c|c|c|}
\hline Study & $\begin{array}{l}\text { Sampling / Recruitment Strategy }{ }^{\text {a }} \text {, Data Collection } \\
\text { Period }\end{array}$ & Study Findings \\
\hline
\end{tabular}

be former smokers with restriction 1 ( $\mathrm{AOR}=0.81,95 \% \mathrm{Cl}$ :

$0.67,0.98)$ and across all four additional sample

restrictions with the range of AORs from 0.68 to 0.81 .

White menthol smokers had significantly lower odds of being a former smoker ( $\mathrm{AOR}=0.93,95 \% \mathrm{Cl}: 0.88,0.98$ ) across three of the five sample restrictions (1, 2 and 3$)$. Puerto Rican menthol smokers were consistently and significantly less likely to be former smokers across all five sample restrictions, with AORs ranging from 0.42 to 0.63 .

Increase with Menthol Cigarette Use

Two of the five sample restrictions (2 and 4) reported significantly higher odds of being a former smoker among Mexican menthol, versus non-menthol, smokers with AORs of 1.34 and 1.35 , respectively.

No difference

No difference between menthol and non-menthol smokers was found in the adjusted odds of being a former smoker for the overall sample (AOR $=0.922,95 \%$ Cl: 0.847 to 1.004$)$.

Also, no difference between White menthol and nonmenthol smokers in the odds of being a former smoker (restrictions 4 and 5); likewise, no difference between Hispanic menthol and non-menthol smokers (restrictions 1 to 4); and, no difference between Mexican menthol and non-menthol smokers (restrictions 1, 3, and 5).

Reitzel, 2011c; Reitzel et al., 2011 $[58,59]$

Trinidad et al., 2010 [69]

Gandhi et al., 2009 [37]
Project MOM;

2005-2007

TUS-CPS;

2003, 2006-2007
Decrease with Menthol Cigarette Use

Adjusting for age, partner status, income, and educational achievement, time, treatment group, CPD, and time to the first cigarette of the day, White female menthol, versus non-menthol, cigarette smokers were significantly less likely to maintain continuous abstinence $(\beta=-1.62, \mathrm{SE}=0.76 ; \times 2=4.49 ; p=0.03 ; \mathrm{AOR}=0.19,95 \%$ Cl: 0.04 to 0.89 ).

No Difference

Across the entire sample, no difference between menthol and non-menthol use in continuous abstinence from smoking through 26 weeks postpartum $(\beta=-0.32$, $\mathrm{SE}=0.30 ; p=0.29 ; n=297$.

No difference between Black female menthol and nonmenthol smokers in continuous abstinence $(\beta=-1.12$, $\mathrm{SE}=.64 ; \mathrm{C} 2=3.06 ; p=.08 ; n=96) ;$ likewise, no difference between Latina female menthol and non-menthol smokers in continuous abstinence $(\beta=.46, \mathrm{SE}=.50$; $\mathrm{c} 2=.86 ; p=.35 ; n=93$ ).

Descrease with Menthol Cigarette Use

The odds of successful quiting for $\geq 6$ months among former smokers was significantly less likely in menthol, versus non-menthol, smokers, across all race/ethnicity subgroups evaluated: White smokers (AOR $=0.28,95 \%$ Cl: 0.25 to 0.33 ); Black smokers ( $\mathrm{AOR}=0.23,95 \% \mathrm{Cl}: 0.17$ to 0.31); Asian-American/Pacific Islander smokers (AOR = $0.22,95 \% \mathrm{Cl}: 0.11$ to 0.45 ); and Hispanic/Latino smokers (AOR $=0.48,95 \%$ Cl: 0.34 to 0.69 ).

No Difference

No difference between Native American/Alaskan Native former menthol and non-menthol smokers in the odds of successful quiting for $\geq 6$ months ( $A O R=0.49,95 \% \mathrm{Cl}$ : 0.14 to 1.71$)$.

Decrease with Menthol Cigarette Use

The odds of Black menthol, versus non-menthol, smokers' abstinence were significantly lower at 4 weeks (measured by 7-day PPA (AOR $=0.32,95 \% \mathrm{Cl}: 0.16$ to 0.62 ) and at 6 months post-quit (AOR $=0.48,95 \% \mathrm{Cl}: 0.25$ to 0.90$)$.

Hispanic menthol, versus non-menthol, smokers' odds of
Outpatient tobacco treatment clinic patients; January 2001-June 2005 
Table 7 Summary of Evidence Related to Rate of Abstinence/Quitting (Continued)

\begin{tabular}{|c|c|c|c|}
\hline Study & $\begin{array}{l}\text { Sampling / Recruitment Strategy }{ }^{\mathrm{a}} \text {, Data Collection } \\
\text { Period }\end{array}$ & Study Findings & $\begin{array}{l}\text { Study } \\
\text { Quality }\end{array}$ \\
\hline & & $\begin{array}{l}\text { abstinence at } 4 \text { weeks post-quit were also significantly } \\
\text { lower (AOR }=0.43,95 \% \mathrm{Cl}: 0.1 \text { to } 0.9 \text { ). } \\
\text { No Difference } \\
\text { No difference between White menthol and non- } \\
\text { menthol smokers in the likelihood of abstinence at } 4 \\
\text { weeks (AOR }=0.96,95 \% \mathrm{Cl}: 0.72 \text { to } 1.20 \text { ) or } 6 \text { months } \\
\text { post-quit (AOR }=1.0,95 \% \mathrm{Cl}: 0.8 \text { to } 1.4 \text { ). Also, no differ- } \\
\text { ence between Hispanic menthol and non-menthol } \\
\text { smokers in the odds of abstinence at } 6 \text { months (AOR= } \\
0.64,95 \% \mathrm{Cl}: 0.2 \text { to } 1.80 \text { ). }\end{array}$ & \\
\hline $\begin{array}{l}\text { Gundersen et al., } \\
2009 \text { [39] }\end{array}$ & NHIS-CCS; 2005 & $\begin{array}{l}\text { Decrease with Menthol Cigarette Use } \\
\text { Subgroup analysis found that Hispanic menthol, versus } \\
\text { non-menthol, smokers were significantly less likely to } \\
\text { have quit smoking (AOR }=0.61,95 \% \text { Cl: } 0.39 \text { to } 0.97 ; p= \\
0.04 \text { ). } \\
\text { When Black and Hispanic smokers were combined } \\
\text { (defining a "non-White" subsample), non-White menthol, } \\
\text { versus non-menthol, smokers were significantly less } \\
\text { likely to have quit smoking (AOR }=0.55,95 \% \text { Cl: } 0.43 \text { to } \\
0.71 ; p<0.01 \text { ). } \\
\text { Increase with Menthol } \\
\text { Subgroup analysis found that White menthol, versus } \\
\text { non-menthol, smokers were significantly more likely to } \\
\text { have quit smoking (AOR }=1.17,95 \% \text { Cl: } 1.00 \text { to } 1.36 ; p< \\
0.05 \text { ). } \\
\text { No difference } \\
\text { Without stratifying for race/ethnicity, no difference } \\
\text { between menthol and non-menthol smokers in smoking } \\
\text { cessation (AOR }=1.05,95 \% \text { Cl: } 0.92 \text { to } 1.21 \text { ). } \\
\text { Subgroup analysis: no difference between Black menthol } \\
\text { and non-menthol smokers in the odds of smoking ces- } \\
\text { sation (AOR }=0.78,95 \% \mathrm{Cl}: 0.56 \text { to } 1.09 \text { ). }\end{array}$ & Good \\
\hline $\begin{array}{l}\text { Okuyemi et al., } \\
2003 \text { [51] }\end{array}$ & KIS trial; August 2000-November 2000. & $\begin{array}{l}\text { Decrease with Menthol Cigarette Use } \\
\text { Although biochemically verified 7-day PPA abstinence } \\
\text { was measured at both } 6 \text { weeks and } 6 \text { months, authors } \\
\text { only modeled for } 6 \text { weeks "because univariate analysis } \\
\text { did not reveal significant differences in abstinence rates } \\
\text { between menthol and non-menthol smokers at } 6 \\
\text { months." In addition, overall modeled results were not } \\
\text { presented. } \\
\text { Among adults }<50 \text { years of age, non-menthol, versus } \\
\text { menthol, smokers had significantly higher odds of quit- } \\
\text { ting (AOR }=2.02,95 \% \mathrm{Cl}: 1.03 \text { to 3.95). } \\
\text { No Difference } \\
\text { No difference between menthol and non-menthol } \\
\text { smokers }>50 \text { years of age in abstinence rates }(p=0.57) \text {. }\end{array}$ & Good \\
\hline
\end{tabular}

${ }^{a}$ Details of sampling and recruitment strategies for the data sources can be found in Table 3: Study, Data Set, and Sample Characteristics

term abstinence for the overall sample. However, among White participants, menthol use predicted a significant decrease in short-term abstinence $(\beta=-1.56, \mathrm{SE}=0.79$; $\left.\chi^{2}=3.96 ; p=0.05\right)$ as well as 7-day PPA $(\beta=-1.60, \mathrm{SE}=$ $\left.0.79 ; \chi^{2}(1)=4.06 ; p=.04 ; n=132\right)$. No such differences were reported for either outcome among Black participants (short-term abstinence: $\beta=0.54, \mathrm{SE}=0.55 ; p=$ 0.33; and 7-day PPA: $\beta=1.00, \mathrm{SE}=0.67 ; p=0.11$ ).

Blot et al. [27] found that White menthol smokers had significantly greater odds of having quit compared with non-menthol smokers $(\mathrm{AOR}=1.55,95 \% \mathrm{CI}$ : 1.41 to 1.70); however, Black menthol and non-menthol smokers were no different.
Trinidad et al. [69] reported that, among White, Black, Asian-American/Pacific Islander, and Hispanic participants, menthol smoking was associated with significantly lower odds of abstinence greater than 6 months (AORs ranged from 0.28 to 0.48 ). However, among Native American/Alaskan native participants, menthol and non-menthol smokers were no different in terms of the odds of abstinence greater than 6 months.

Delnevo et al. [31, 32] reported on the odds of being a former smoker across five racial/ethnic subgroups and the following five sample restrictions (according to past and current smoking status): former smokers who quit within the past 5 years and all current smokers 
Table 8 Summary of Evidence Related to Change in Smoking Quantity/Frequency

\begin{tabular}{|c|c|c|}
\hline Study & $\begin{array}{l}\text { Sampling / Recruitment Strategy }{ }^{a} \text {, Data Collection } \\
\text { Period }\end{array}$ & Study Findings \\
\hline \multicolumn{3}{|c|}{ Increase in Smoking Quantity/Frequency with Menthol Cigarette Use } \\
\hline $\begin{array}{l}\text { Azagba et al., } \\
2020 \text { [26] }\end{array}$ & $\begin{array}{l}\text { NYTS; } \\
\text { 2017-2018 }\end{array}$ & $\begin{array}{l}\text { Significantly higher odds of using at least } 10 \text { days (versus } \\
\text { ( } 1-9 \text { days) in the past } 30 \text { days compared with non- } \\
\text { menthol cigarette smokers, in the full sample (AOR }=1.48 \text {, } \\
95 \% \mathrm{Cl}, 1.14 \text { to } 1.94 ; p<0.05 \text { ) and in the stratified analyses } \\
\text { for both middle school students ( } \mathrm{AOR}=2.36,95 \% \mathrm{Cl}, 1.01 \\
\text { to } 5.49 ; p<0.05 \text { ) and high school students ( } \mathrm{AOR}=1.41 \text {, } \\
95 \% \mathrm{Cl}, 1.09 \text { to } 1.82 ; p<0.05 \text { ). } \\
\text { Significantly higher odds of using at least } 20 \text { days (versus } \\
(1-19 \text { days) in the past } 30 \text { days compared with non- } \\
\text { menthol cigarette smokers, in the full sample } \mathrm{AOR}=1.62 \text {, } \\
95 \% \mathrm{Cl}, 1.15 \text { to } 2.28 ; p<0.05 \text { ) and in the stratified analyses } \\
\text { for both middle school students ( } \mathrm{AOR}=3.76,95 \% \mathrm{Cl}, 1.21 \\
\text { to } 11.71 ; p<0.05 \text { ) and high school students (AOR }=1.49 \text {, } \\
95 \% \mathrm{Cl}, 1.07 \text { to } 2.07 ; p<0.05 \text { ). }\end{array}$ \\
\hline
\end{tabular}

Study Quality

No Difference in Change in Smoking Quantity/Frequency with Menthol Cigarette Use

\author{
Hyland et al., COMMIT; \\ 2002 [40]; Hyland 1988-2001 \\ \& Rivard, 2010 \\ [41]
}

Gubner et al., 2018 [38]
Sawdey et al., NYTS:

2020 [62] 2011-2018

Reitzel, 2011c [58] Project MOM; 2005-2007

\begin{abstract}
No difference between menthol and non-menthol smokers in the odds of reducing daily cigarette use over 3 years ( $\mathrm{AOR}=0.83,95 \% \mathrm{Cl}: 0.64$ to 1.07 ); subgroup analyses of Black and White smokers also found no difference. Similarly, change in CPD in 1993 according to cigarette type smoked in 1988 was no different in the overall sample ( $\beta$-coefficient $=0.11,95 \% \mathrm{Cl}:-0.38$ to 0.60$)$, nor in Black, White, or Hispanic subgroups.

Applying an adjusted logistic regression model, the study found that the number of CPD was not significantly associated with menthol use (AOR $=1.01,95 \% \mathrm{Cl}: 0.98$ to 1.00; $p=0.48$ ).
\end{abstract}

Drug Abuse Clinical Trials Network), with selfadministered surveys conducted during on-site visits; April to December 2015

Results with Mixed Significance in Smoking Quantity/Frequency

Decrease with Menthol Cigarette Use

Black female menthol, versus non-menthol, smokers reported substantially less cigarette reduction (measured by CPD) over the course of 26 weeks $(\beta=3.82, \mathrm{SE}=3.77 ; p=$ $0.02 ; n=71)$.

No Difference

No difference among female menthol and non-menthol smokers, overall, in changes in smoking frequency over the 26-week period $(\beta=-0.38, \mathrm{SE}=1.15 ; \mathrm{t}=-.33 ; p=.74$; $n=222$ ).

Increase with Menthol Cigarette Use

Odds of frequent smokers (on $\geq 20$ days in the past 30 days) being menthol smokers was significantly higher than being non-menthol smokers $(\mathrm{AOR}=1.57,95 \% \mathrm{Cl}$ : 1.08-2.29).

No Difference

No significant difference in the odds of moderate smokers (on 6 to 19 days in the past 30 days) being menthol versus non-menthol smokers ( $\mathrm{AOR}=1.17,95 \% \mathrm{Cl}$ : 0.86-1.59). The overall $p=$ value across both groups - frequent and moderate smokers-was non-significant $(p=0.064)$.

\footnotetext{
${ }^{a}$ Details of sampling and recruitment strategies for the data sources can be found in Table 3: Study, Data Set, and Sample Characteristics
}

(regardless of quit attempt history); former smokers who quit within the past 5 years and all current smokers (regardless of quit attempt history), both of whom currently do not use other tobacco products; former smokers who quit within the past 5 years and current smokers who reported ever having made a quit attempt; former smokers who quit within the past 5 years and current smokers who reported ever having made a quit attempt, both of whom currently do not use other tobacco products; and, past 12-month cigarette smokers who made a quit attempt or quit (i.e., former smokers). Among the overall sample, across four of the five restrictions, menthol 
Table 9 Summary of Evidence Related to Return to Smoking/ Relapse

\begin{tabular}{|c|c|c|c|}
\hline Study & $\begin{array}{l}\text { Sampling / } \\
\text { Recruitment } \\
\text { Strategy }^{\mathrm{a}} \text {, Data } \\
\text { Collection Period }\end{array}$ & Study Findings & $\begin{array}{l}\text { Study } \\
\text { Quality }\end{array}$ \\
\hline \multicolumn{4}{|c|}{ Increased Return to Smoking/Relapse with Menthol Cigarette Use } \\
\hline $\begin{array}{l}\text { Muench } \\
\& \\
\text { Juliano, } \\
2017 \\
{[48]}\end{array}$ & $\begin{array}{l}\text { Sample was recruited } \\
\text { from the Washington } \\
\text { DC metropolitan area } \\
\text { through flyers, word of } \\
\text { mouth, and online } \\
\text { advertisements }\end{array}$ & $\begin{array}{l}\text { According to logistic } \\
\text { regression model results, } \\
\text { menthol cigarette use } \\
\text { was significantly } \\
\text { associated with greater } \\
\text { lapse risk (AOR = 3.474, } \\
p<0.05 \text { ). Similarly, } \\
\text { menthol, versus non- } \\
\text { menthol, use was signifi- } \\
\text { cantly higher for risk of } \\
\text { lapsing within the first } \\
48 \mathrm{~h} \text { of abstinence (HR= } \\
2.798, \text { Wald statistic }= \\
2.79 ; p=0.048 \text { ). }\end{array}$ & Good \\
\hline $\begin{array}{l}\text { Pletcher } \\
\text { et al., } \\
2006 \\
{[54]}\end{array}$ & CARDIA; 1985-2000 & $\begin{array}{l}\text { The odds of returning to } \\
\text { smoking post-cessation } \\
\text { were significantly higher } \\
\text { for menthol, versus non- } \\
\text { menthol, smokers } \\
\text { (AOR }=1.89,95 \% \mathrm{Cl}: 1.17 \\
\text { to } 3.05 ; p=0.009 \text { ). }\end{array}$ & Good \\
\hline
\end{tabular}

a Details of sampling and recruitment strategies for the larger and/or national surveys can be found in Table 3: Study, Data Set, and Sample Characteristics

cigarette smokers were significantly less likely than nonmenthol smokers to be former smokers with AORs ranging from 0.90 to 0.92 .

Black menthol smokers were significantly less likely to be former smokers compared to Black non-menthol smokers in all five restrictions with AORs ranging from 0.68 to 0.81 . White menthol, versus non-menthol, smokers were significantly less likely to be a former smoker across three restrictions. However, Hispanic menthol and non-menthol smokers were no different across four of the five restrictions; and, were significantly less likely to be a former smoker in one restriction.

In Reitzel's 'Project Mom' [58, 59], menthol cigarette use did not predict continuous abstinence from smoking. However, among White women, menthol smokers were significantly less likely to maintain continuous abstinence compared to non-menthol smokers $(\mathrm{AOR}=$ 0.19 , $95 \%$ CI: 0.04 to 0.89 ).

Gandhi et al. [37] found no difference between White menthol and non-menthol smokers in odds of abstinence at both 4 weeks and 6 months. Black menthol smokers had significantly lower odds of abstinence compared to Black non-menthol smokers at both time points, 4 weeks (measured by 7-day PPA) $(\mathrm{AOR}=0.32$, $95 \%$ CI: 0.16 to 0.62$)$ and at 6 months post-quit (AOR = 0.48, 95\% CI: 0.25 to 0.90). Hispanic menthol smokers had significantly lower odds of abstinence at 4 weeks compared to Hispanic non-menthol smokers $(\mathrm{AOR}=$ 0.43, 95\% CI: 0.1 to 0.9); at 6 months, Hispanic menthol and non-menthol smokers were no different in odds of abstinence.

Gundersen et al. [39] suggested no significant difference in being a former smoker between menthol and non-menthol smokers in the overall sample, and among Black smokers. However, odds of being a former smoker were significantly higher for White menthol compared to White non-menthol smokers (AOR $=1.17,95 \% \mathrm{CI}$ : 1.00 to $1.36 ; p<0.05)$. Odds of being a former smoker were significantly lower for Hispanic menthol compared to Hispanic non-menthol smokers (AOR $=0.61,95 \% \mathrm{CI}$ : 0.39 to $0.97 ; p=0.04$ ), and for non-White menthol compared to non-White non-menthol smokers $(\mathrm{AOR}=0.55$, 95\% CI: 0.43 to $0.71 ; p<0.01)$.

Okuyemi et al. [51] reported no significant difference in odds of quitting between menthol and non-menthol smokers among adults $\geq 50$ years of age; however, in adults $<50$ years of age, the odds of quitting for menthol smokers were significantly lower for menthol smokers (AOR $=2.02,95 \%$ CI: 1.03 to 3.95$)$.

Across the 28 studies, the majority of studies (15 studies) found no difference between menthol and nonmenthol smokers in the rate of abstinence. Four studies reported that menthol smokers were significantly less likely to quit smoking and nine studies reported results of mixed significance based on various stratifications. Overall, the evidence for this outcome was inconsistent for the association between menthol cigarette use and the rate of abstinence/quitting.

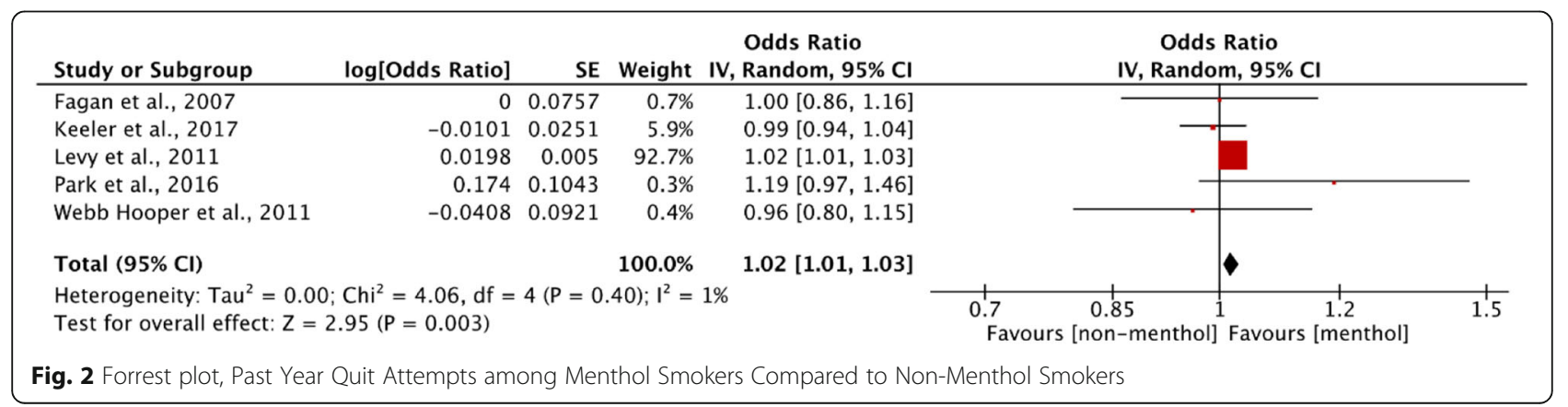




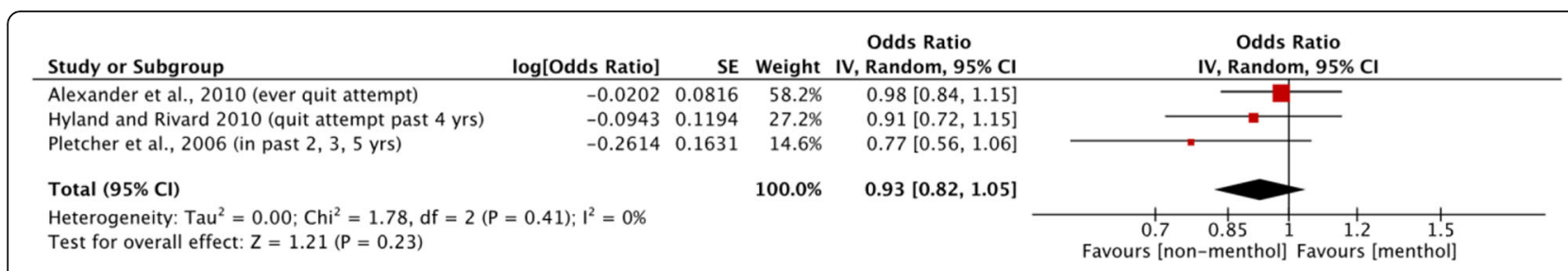

Fig. 3 Forrest plot, Ever Quit Attempts among Menthol Smokers Compared to Non-Menthol Smokers

\section{Change in smoking quantity/frequency}

Five studies (from six references), presented in Table 8, provided adjusted analysis of change in smoking quantity/frequency.

Azagba et al. [26] found that menthol cigarette smokers had significantly higher odds of using cigarettes at least 10 days (versus (1-9 days) in the past 30 days compared with non-menthol cigarette smokers, in the full sample $(\mathrm{AOR}=1.48,95 \% \mathrm{CI}, 1.14$ to $1.94 ; p<0.05)$ and among both middle $(\mathrm{AOR}=2.36,95 \% \mathrm{CI}, 1.01$ to 5.49; $p<0.05)$ and high school students $(\mathrm{AOR}=1.41$, $95 \% \mathrm{CI}, 1.09$ to $1.82 ; p<0.05)$. Similarly, menthol cigarette smokers had significantly higher odds of using at least 20 days (versus (1-19 days) in the past 30 days compared with non-menthol cigarette smokers, in the full sample $\mathrm{AOR}=1.62,95 \% \mathrm{CI}, 1.15$ to $2.28 ; p<0.05$ ) and among both middle ( $\mathrm{AOR}=3.76,95 \% \mathrm{CI}, 1.21$ to $11.71 ; p<0.05)$ and high school students $(\mathrm{AOR}=1.49$, 95\% CI, 1.07 to $2.07 ; p<0.05$ ).

One study, from two references [40,41], reported no difference between menthol and non-menthol cigarette smokers for changes in smoking frequency; similarly, one study reported that cigarettes per day (CPD) was not significantly associated with menthol cigarette use [38].
Two studies reported mixed significance. Reitzel [58] found that Black female menthol smokers reported substantially less cigarette reduction (measured by CPD) over the course of 26 weeks $(\beta=3.82, \mathrm{SE}=3.77 ; p=0.02 ; n=$ 71 ), but no difference was found in changes in smoking frequency for the overall sample. Sawdey et al. [62] found no significant difference in the odds of moderate smokers (on 6 to 19 days in the past 30 days) being menthol versus non-menthol smokers (AOR $=1.17,95 \% \mathrm{CI}$ : 0.86-1.59); however, the odds of frequent smokers (on $\geq 20$ days in the past 30 days) being menthol smokers was significantly higher than being non-menthol smokers $(\mathrm{AOR}=1.57$, 95\% CI: 1.08-2.29). The overall $\mathrm{p}=$ value across both groups was non-significant $(p=0.064)$.

The overall evidence base for this outcome was limited by the small number of included studies, and the mixed significance of findings across studies precludes clear conclusions from the available evidence.

\section{Return to smoking/relapse}

Two studies, presented in Table 9, provided analyses of return to smoking/relapse.

In Muench and Juliano [48], menthol smokers were at a significantly greater risk of lapsing compared with

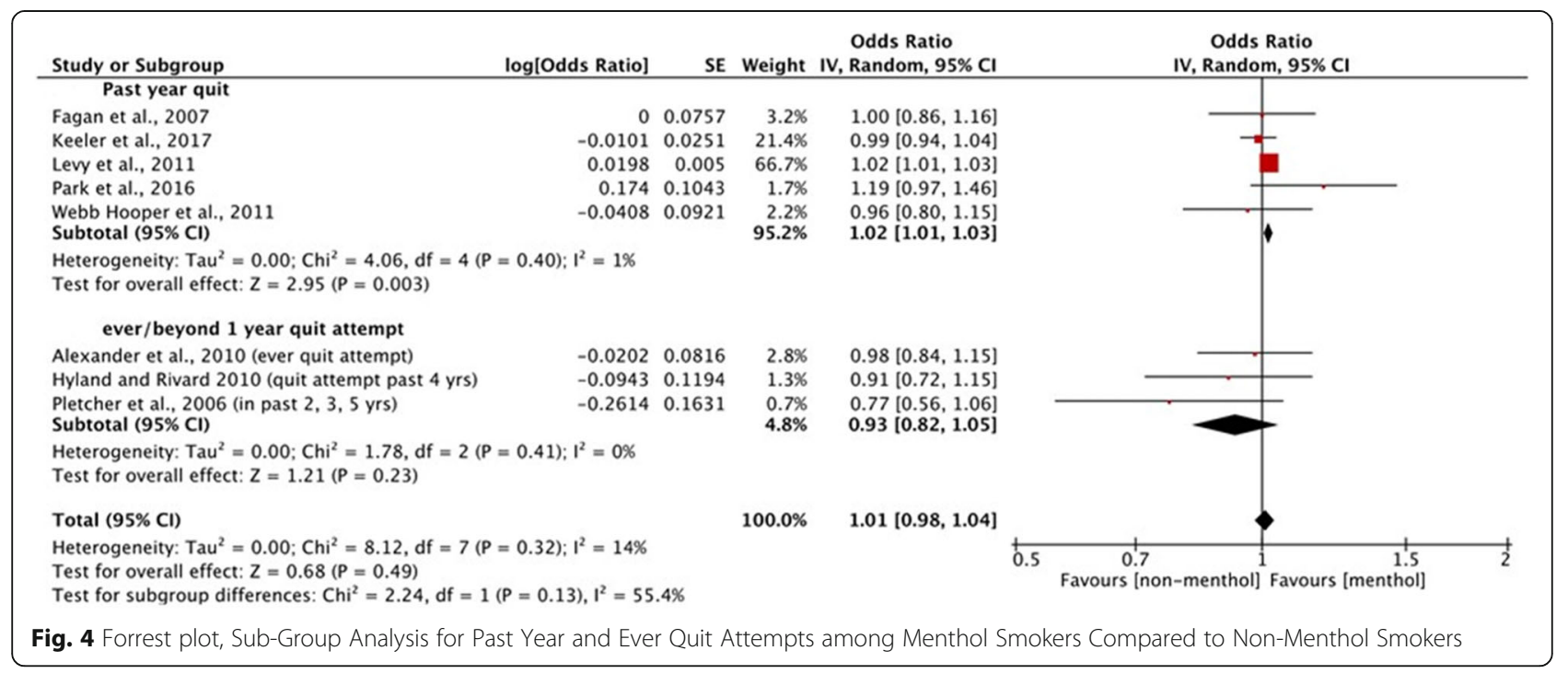




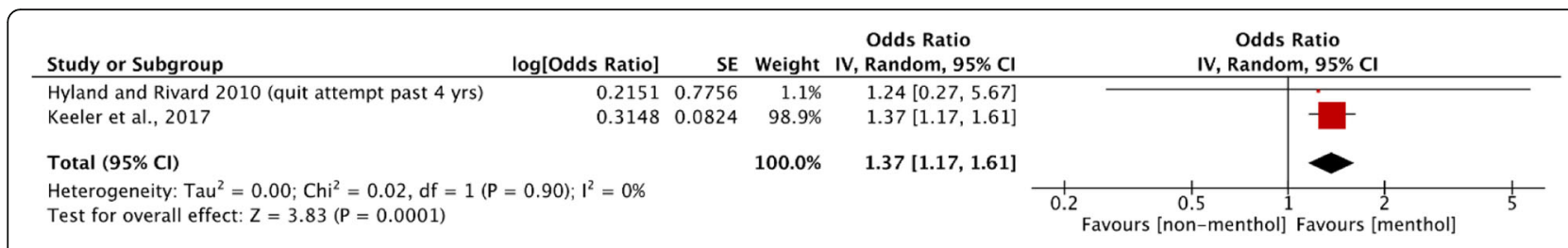

Fig. 5 Forrest plot, Ever Quit Attempts among Black Respondents

non-menthol smokers, in both the univariate regression $(\mathrm{AOR}=3.474, p<0.05)$ and lapse survival curve analyses $(\mathrm{HR}=2.798$, Wald statistic $=2.79 ; p=0.048)$. Pletcher et al. [54] reported that young adult menthol smokers had a significantly higher likelihood of returning to smoking, compared to non-menthol smokers $(\mathrm{AOR}=$ 1.89, $95 \%$ CI: 1.17 to $3.05 ; p=0.009$ ).

These results suggest a higher likelihood of menthol smokers relapsing. However, the small number of studies-neither based on nationally representative samples-limit the generalizability of the findings.

\section{Sensitivity analyses}

Three sensitivity analyses were conducted in order to test whether the results differed after more stringent inclusion and exclusion criteria were applied. Overall, results from the sensitivity analyses suggested little to no change. Full details on the sub-group analysis and sensitivity analyses are provided in SUPPLEMENTAL SECTION 5: Sensitivity Analyses.

\section{Results of meta-analyses}

After screening all included adjusted studies, pooled data were included and extracted for two outcome measures: nine studies in the meta-analyses for quit attempts [25, $33,41,42,44,46,53,54,70]$ and 12 studies for abstinence [27, 32, 34-37, 39, 51, 52, 54, 61, 66]. Full details are provided in SUPPLEMENTAL SECTION 6: Characteristics, Definitions, and Covariates of Studies Included in the Meta-Analysis.

\section{Adjusted odds of reporting a quit attempt (past year or ever)}

Results from five studies were pooled to measure the association of menthol use and past year quit attempts.
Pooled results from five studies (Fig. 2) showed a significant association between menthol, versus non-menthol, cigarette use and the increasing odds for past year quit attempts $(\mathrm{OR}=1.02,95 \% \mathrm{CI}: 1.01$ to $1.03, p$-value $=$ $0.003, \mathrm{I} 2=1 \%)$. However, pooled result was different for a group of studies measuring ever quit attempts (Alexander et al. [2010]: AOR $=0.98,95 \%$ CI: 0.83 to 1.15), any quit attempts between 2001 to 2005 (Hyland and Rivard, [2010]: AOR $=0.91,95 \%$ CI: 0.72 to 1.15), and any quit attempt in the past 2, 3, or 5 years (Pletcher et al. [2006]: $0.77,95 \%$ CI: 0.57 to 1.06 ), finding no significant difference in the odds of making a quit attempt among menthol users compared to non-menthol cigarette smokers $(\mathrm{OR}=0.93,95 \% \mathrm{CI}, 0.82$ to $1.05, p=$ 0.23 , I2 $=0 \%$; Fig. 3 ) $[25,41,54]$. In a subgroup analysis of the five studies with past year quit attempts as one group, and the group of three studies measuring ever quit attempts, any quit attempts between 2001 to 2005 , and any quit attempt in the past 2,3 , or 5 years (Fig. 4), results remained non-significant $(\mathrm{OR}=1.01$, 95\% CI: 0.98 to $1.04, p=0.49, \mathrm{I} 2=14 \%)$. Test for subgroup difference showed moderate heterogeneity $(\mathrm{I} 2=55.4 \%)$.

Results from two studies were pooled to measure for the association of menthol cigarette use and quit attempts (past year and quit attempts between 2001 and 2005) among Black participants (Fig. 5) [41, 44]. Pooled results showed a significant increase in the odds of Black menthol, versus non-menthol, smokers reporting quit attempts $(\mathrm{OR}=1.37,95 \% \mathrm{CI}: 1.17$ to $1.61, p=0.00001$, $\left.\mathrm{I}^{2}=14 \%\right)$. In contrast, among White menthol respondents in three studies (Fig. 6), the odds of making a quit attempt were significantly lower for menthol compared to non-menthol smokers $(\mathrm{OR}=0.95,95 \% \mathrm{CI}: 0.91$ to $\left.0.99, \mathrm{I}^{2}=0 \%\right)[41,42,44]$.

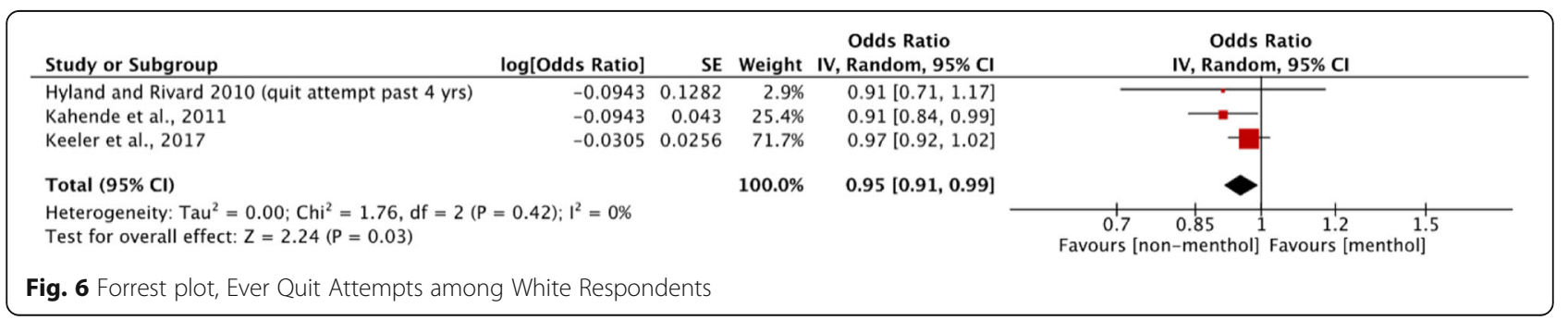




\begin{tabular}{|c|c|c|c|c|c|c|}
\hline Study or Subgroup & log[Odds Ratio] & SE & Weight & $\begin{array}{l}\text { Odds Ratio } \\
\text { IV, Random, } 95 \% \mathrm{CI}\end{array}$ & $\begin{array}{l}\text { Odds Ratio } \\
\text { IV, Random, } 95 \% \mathrm{CI}\end{array}$ & \\
\hline \multicolumn{7}{|l|}{ Cross-Sectional } \\
\hline Delnevo et al., 2011 & -0.0943 & 0.0273 & $41.5 \%$ & $0.91[0.86,0.96]$ & - & \\
\hline $\begin{array}{l}\text { Gundersen et al., } 2009 \\
\text { Subtotal }(95 \% \mathrm{Cl})\end{array}$ & 0.0488 & 0.0724 & $\begin{array}{l}25.0 \% \\
66.4 \%\end{array}$ & $\begin{array}{l}1.05[0.91,1.21] \\
0.96[0.84,1.10]\end{array}$ & & \\
\hline \multicolumn{7}{|c|}{$\begin{array}{l}\text { Heterogeneity: } \mathrm{Tau}^{2}=0.01 ; \mathrm{Chi}^{2}=3.42, \mathrm{df}=1(\mathrm{P}=0.06) ; \mathrm{I}^{2}=71 \% \\
\text { Test for overall effect: } \mathrm{Z}=0.55(\mathrm{P}=0.58)\end{array}$} \\
\hline \multicolumn{7}{|c|}{ Prospective Cohort } \\
\hline Blot et al., 2011 & 0.0198 & 0.0656 & $27.3 \%$ & $1.02[0.90,1.16]$ & & \\
\hline $\begin{array}{l}\text { Pletcher et al., } 2006 \\
\text { Subtotal }(95 \% \mathrm{Cl})\end{array}$ & -0.3567 & 0.1971 & $\begin{array}{r}6.3 \% \\
33.6 \%\end{array}$ & $\begin{array}{l}0.70[0.48,1.03] \\
\mathbf{0 . 8 8}[0.62,1.27]\end{array}$ & & \\
\hline \multicolumn{7}{|c|}{$\begin{array}{l}\text { Heterogeneity: } \mathrm{Tau}^{2}=0.05 ; \mathrm{Chi}^{2}=3.28, \mathrm{df}=1(\mathrm{P}=0.07) ; \mathrm{I}^{2}=70 \% \\
\text { Test for overall effect: } \mathrm{Z}=0.67(\mathrm{P}=0.50)\end{array}$} \\
\hline Total $(95 \% \mathrm{Cl})$ & & & $100.0 \%$ & $0.96[0.86,1.06]$ & & \\
\hline \multicolumn{7}{|c|}{$\begin{array}{l}\text { Heterogeneity: } \mathrm{Tau}^{2}=0.01 ; \mathrm{Chi}^{2}=7.47, \mathrm{df}=3(\mathrm{P}=0.06) ; \mathrm{I}^{2}=60 \% \\
\text { Test for overall effect: } \mathrm{Z}=0.83(\mathrm{P}=0.41) \\
\text { Test for subgroup differences: } \mathrm{Chi}^{2}=0.19, \mathrm{df}=1(\mathrm{P}=0.67), \mathrm{I}^{2}=0 \%\end{array}$} \\
\hline \multicolumn{7}{|c|}{ Fig. 7 Forrest plot, Abstinence with no Specified Duration between Study Designs and All Studies } \\
\hline
\end{tabular}

Adjusted odds of abstinence (no definition and 7-day PPA) Four studies presented results for the association of menthol use and abstinence (self-reported) with no specified duration of abstinence. Two of the studies were cross-sectional in design [32, 39], and two were prospective cohort $[27,54]$. Pooled results of cross-sectional studies showed that odds of abstinence with no defined duration among menthol smokers compared to nonmenthol smokers was not significant $(\mathrm{OR}=0.96,95 \% \mathrm{CI}$ : 0.84 to $1.10, p=0.58, \mathrm{I}^{2}=71 \%$ ). A non-significant result was likewise found in synthesis of prospective cohorts (OR $=0.88$, 95\% CI: 0.62 to $\left.1.27, p=0.50, \mathrm{I}^{2}=70 \%\right)$. Synthesizing the results of the four studies showed that the association of abstinence with no defined duration among menthol smokers compared to non-menthol smokers was not significant $(\mathrm{OR}=0.96,95 \% \mathrm{CI}$ : 0.86 to 1.06, $p=0.41, \mathrm{I}^{2}=60 \%$; Fig. 7). Test of subgroup differences between both groups (cross-sectional and longitudinal) manifested low heterogeneity $\left(\mathrm{I}^{2}=0 \%\right)$.

Three studies presented results for the association of menthol use and abstinence with no specified duration of abstinence for Black participants [27, 32, 39]. Pooled results (Fig. 8) showed that the association between abstinence with no defined duration among menthol smokers compared to non-menthol smokers was not significant $(\mathrm{OR}=0.90,95 \% \mathrm{CI}: 0.73$ to $1.10, p=0.29$, $\left.\mathrm{I}^{2}=73 \%\right)$. Studies likewise allowed for analysis of association of menthol use and abstinence from smoking with no specified duration of abstinence for White participants [27, 32, 39]. Similar to Black participants, among White participants, results showed that the association of abstinence with no defined duration among menthol smokers compared to non-menthol smokers was not significant $(\mathrm{OR}=1.19,95 \% \mathrm{CI}: 0.83$ to $1.69, p=0.34$, $=98 \%$; Fig. 9). The heterogeneity was noted to be high for this analysis.

Four cohort studies presented results for the association of menthol use and abstinence from smoking measured by 7-day PPA. For purposes of the following analysis, the studies were grouped by their specific research design. Two of the studies were analyses of RCT by design $[36,61]$, and two were cohort in nature [35, 66]. Seven-day PPA was self-reported at 4 weeks followup for Foulds et al. [35], self-reported at 2 years for $\mathrm{Fu}$ et al. [36], and self-reported and eCO verified for Steinberg et al. [66] and Rojewski et al. [61] at 26 weeks follow-up. All published AORs in the study used in the meta-analysis were standardized to have non-menthol use as the reference group [35, 61]. Pooled results of analyses from all four studies (Fig. 10) showed that odds

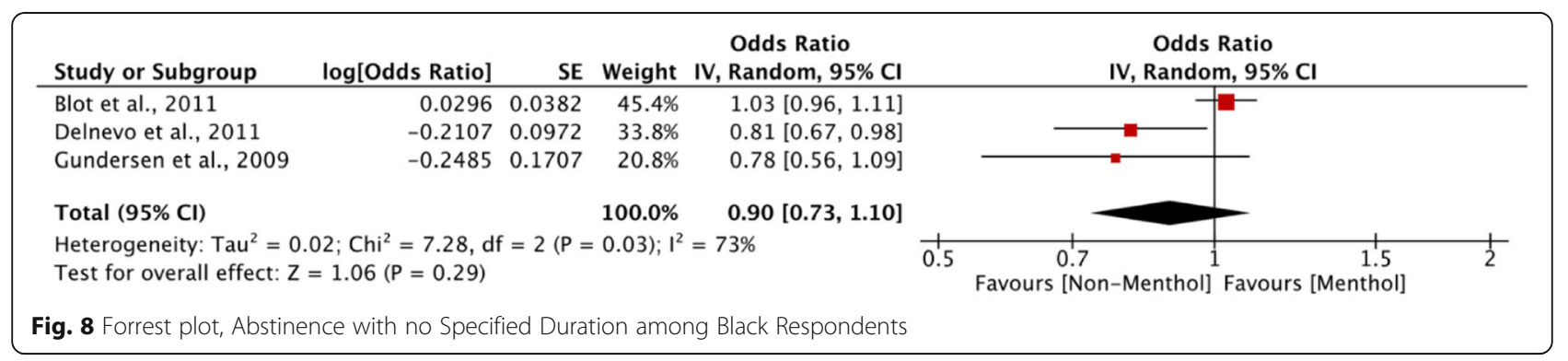




\begin{tabular}{|c|c|c|c|c|c|c|c|c|}
\hline \multirow{2}{*}{$\begin{array}{l}\text { Study or Subgroup } \\
\text { Blot et al., } 2011\end{array}$} & \multirow{2}{*}{$\begin{array}{r}\text { log[Odds Ratio] } \\
0.4383\end{array}$} & \multirow{2}{*}{$\begin{array}{r}\text { SE } \\
0.0471\end{array}$} & \multirow{2}{*}{$\begin{array}{r}\text { Weight } \\
33.6 \%\end{array}$} & \multirow{2}{*}{$\begin{array}{c}\begin{array}{c}\text { Odds Ratio } \\
\text { IV, Random, 95\% Cl }\end{array} \\
1.55[1.41,1.70]\end{array}$} & \multicolumn{4}{|c|}{$\begin{array}{c}\text { Odds Ratio } \\
\text { IV, Random, } 95 \% \mathrm{CI}\end{array}$} \\
\hline & & & & & & & & $\longrightarrow-$ \\
\hline Delnevo et al., 2011 & -0.0726 & 0.0267 & $34.1 \%$ & $0.93[0.88,0.98]$ & & $\rightarrow-$ & & \\
\hline Gundersen et al., 2009 & 0.157 & 0.0768 & $32.3 \%$ & $1.17[1.01,1.36]$ & & & $=$ & \\
\hline Total $(95 \% \mathrm{Cl})$ & & & $100.0 \%$ & $1.19[0.83,1.69]$ & & & & \\
\hline $\begin{array}{l}\text { Heterogeneity: } \operatorname{Tau}^{2}=0 \\
\text { Test for overall effect: } Z\end{array}$ & $\begin{array}{l}\text { 09; } \mathrm{Chi}^{2}=90.77, \mathrm{~d} \\
=0.96(\mathrm{P}=0.34)\end{array}$ & $\mathrm{df}=2(P$ & $<0.0000$ & $1) ; 1^{2}=98 \%$ & 0.5 & $\begin{array}{c}0.7 \\
\text { Favours [Non-Menthe }\end{array}$ & Favours & $\begin{array}{c}1.5 \\
\text { enthol] }\end{array}$ \\
\hline
\end{tabular}

Fig. 9 Forrest plot, Abstinence with no Specified Duration among White Respondents

of 7-day PPA among menthol smokers compared to non-menthol smokers was not significant $(\mathrm{OR}=0.88$, $95 \%$ CI: 0.59 to $\left.1.30, p=0.52, \mathrm{I}^{2}=70 \%\right)$. Similarly, results of longitudinal studies alone and RCT studies alone (Fig. 10) showed that odds of 7-day PPA among menthol smokers compared to non-menthol smokers was not significant (cohort: $\mathrm{OR}=0.83,95 \%$ CI: 0.61 to $1.14, p=$ $0.25, \mathrm{I}^{2}=30 \%$; RCT: OR $=0.78,95 \%$ CI: 0.25 to 2.45 , $\left.p=0.67, \mathrm{I}^{2}=84 \%\right)$. Test for subgroup difference showed low heterogeneity $\left(\mathrm{I}^{2}=0 \%\right)$.

Four studies presented results for the association of menthol use and 7-day PPA among Black participants $[34,37,51,52]$. For the four studies, 7-day PPA was self-reported at 4 weeks follow-up for Gandhi et al. [37], self-reported at 6 weeks for Okuyemi et al. [51], cotinine verified (cut-off $<15 \mathrm{ng} / \mathrm{ml}$ ) for Faseru et al. [34] at 7 weeks follow-up, and cotinine verified (cut-off $<20 \mathrm{ng} / \mathrm{ml}$ ) and $\mathrm{eCO}$ verified $(<10$ ppm) for Okuyemi et al. [52] at 26 weeks follow-up. All published AORs in the study used in the metaanalysis were standardized to have non-menthol use as the reference group [34, 51, 52]. Results showed that the odds for Black menthol smokers exhibiting 7-day PPA were significantly lower when compared to Black non-menthol smokers $(\mathrm{OR}=0.52,95 \% \mathrm{CI}$ : 0.38 to $0.70, p<0.0001, \mathrm{I}^{2}=0$; Fig. 11$)$.

A sensitivity analysis was conducted for $\mathrm{eCO}$ verified 7-day PPA ( $\leq 10$ ppm) with two studies (Fig. 12) [61, 66].
Rojewski et al. [61] was standardized to have nonmenthol use as the reference group. Meta-analysis results showed that the odds for eCO verified 7-Day PPA among menthol smokers compared to non-menthol smokers was not significant $(\mathrm{OR}=0.70,95 \% \mathrm{CI}$ : 0.28 to $\left.1.70, p=0.42, \mathrm{I}^{2}=71 \%\right)$.

\section{Stength of evidence}

Table 10 provides the SOE for the outcome measures used in the current review to examine the association between menthol cigarette use and cessation outcomes. Most measures were "indirect" and limited by the varying and/or undefined measures of abstinence. As presented in Table 11, the overall strength of evidence for an association between menthol cigarette use and smoking cessation was graded as "low" based on deficiencies in the available evidence base.

\section{Discussion}

The findings in this systematic review differ from several existing literature reviews on this topic. The 2013/2015 FDA Report/Addendum [6, 7] concluded that menthol in cigarettes was "likely associated with reduced success in smoking cessation, especially among Black menthol smokers." That finding was not supported by this newer, more comprehensive review. Similarly, the evidence that contributed to this review does not support the conclusion in the 2011 Report by the FDA's Tobacco Products Scientific Advisory Committee [5] that "[e] vidence is

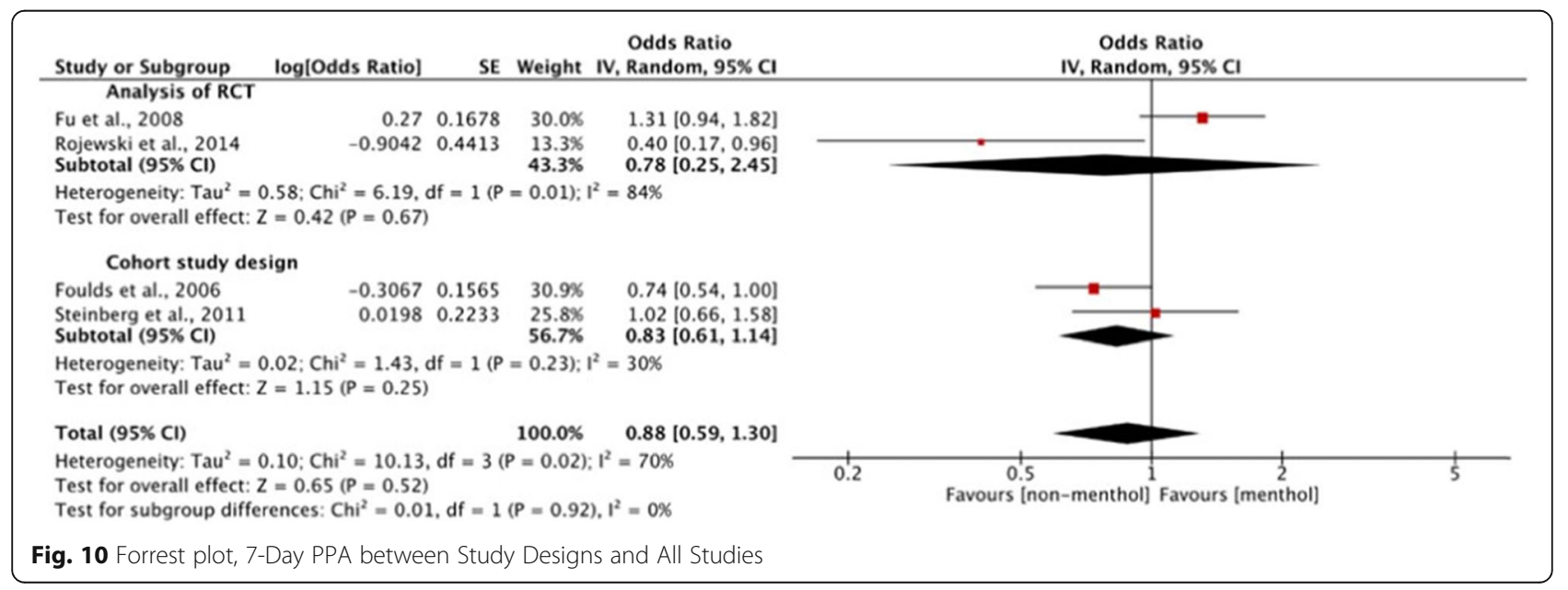




\begin{tabular}{|c|c|c|c|c|c|c|c|}
\hline Study or Subgroup & log[Odds Ratio] & SE & Weight & $\begin{array}{l}\text { Odds Ratio } \\
\text { IV, Random, } 95 \% \mathrm{CI}\end{array}$ & $\begin{array}{r}\text { Odds } \\
\text { IV, Rando }\end{array}$ & $\begin{array}{l}\text { Ratio } \\
\mathrm{m}, \mathbf{9 5 \% \mathrm { Cl }}\end{array}$ & \\
\hline Faseru et al., 2013 & -0.6098 & 0.306 & $25.9 \%$ & $0.54[0.30,0.99]$ & & & \\
\hline Gandhi et al., 2009 & -0.734 & 0.3207 & $23.6 \%$ & $0.48[0.26,0.90]$ & & & \\
\hline Okuyemi et al., 2003 & -0.7031 & 0.3436 & $20.6 \%$ & $0.50[0.25,0.97]$ & & & \\
\hline Okuyemi et al., 2007a (50 y.o. and above) & -0.5164 & 0.4035 & $14.9 \%$ & $0.60[0.27,1.32]$ & & - & \\
\hline Okuyemi et al., 2007a (less than 50 y.o.) & -0.7309 & 0.4023 & $15.0 \%$ & $0.48[0.22,1.06]$ & & & \\
\hline Total $(95 \% \mathrm{Cl})$ & & & $100.0 \%$ & $0.52[0.38,0.70]$ & & & \\
\hline \multicolumn{3}{|c|}{$\begin{array}{l}\text { Heterogeneity: } \mathrm{Tau}^{2}=0.00 ; \mathrm{Chi}^{2}=0.25, \mathrm{df}=4(\mathrm{P}=0.99) ; \mathrm{I}^{2}=0 \% \\
\text { Test for overall effect: } \mathrm{Z}=4.25(\mathrm{P}<0.0001)\end{array}$} & & & \multicolumn{2}{|c|}{$\begin{array}{lccc}0.2 & 0.5 & 1 & 2 \\
\text { Favours [non-menthol] } & \text { Favours [menthol] }\end{array}$} & 5 \\
\hline \multicolumn{5}{|c|}{ Fig. 11 Forrest plot, 7-Day PPA among Black Respondents } & & & \\
\hline
\end{tabular}

sufficient to conclude that a relationship is more likely than not that the availability of menthol cigarettes results in lower likelihood of smoking cessation in Blacks."

Studies in the qualitative synthesis of this review were considered to provide the best available evidence on any differential impact of menthol versus non-menthol cigarette use on smoking cessation. Across studies, a variety of sampling and recruitment methods were used with varying definitions of current smoking and abstinence, and a range of study designs that, in many instances, did not directly address the current research question. Further, the available studies provided evidence that was inconsistent and imprecise-both across studies and within the same study.

Analyses of large cross-sectional studies yielded inconsistent findings. Among studies that used data from nationally representative samples, TUS-CPS and NHIS, population and sub-population results were mixed, based on modeling variation or definitions used; specifically, significantly positive and negative associations between menthol cigarette use and smoking cessation were reported, as well as numerous non-significant findings.

Clinical trials are designed to assess associations between interventions and outcomes, providing the temporal component that cross-sectional data lack. No clinical trials included in this review were designed with menthol cigarette use as the "intervention" to which participants were assigned. Therefore, these studies were reclassified as short-term prospective cohort studies. There was no consistent pattern of a differential impact of menthol versus non-menthol cigarette use on smoking cessation, even when data were stratified by type of cessation intervention, duration of intervention and follow up, or definition of outcome measure (including biochemical validation of self-reported abstinence). Both the shortest (6 weeks) and the longest (12 months) clinical studies found mixed or equivalent results. In addition, trials of cessation inherently include selfselected participants at least interested or motivated to quit smoking. Relying solely-or mainly-on clinical trial data to draw conclusions about the association between menthol cigarette use and smoking cessation will yield a result with limited generalizability to the overall smoking population.

The included prospective studies varied in follow-up duration - a critical factor in assessing the durability of cessation. Of the 11 prospective cohort studies that reported cessation, nine reported outcomes at 6 months or longer post-baseline. Specifically, three reported outcomes at 6 to 12 months, one followed participants for 1 to 2 years, one followed participants for 3 to 5 years, and four assessed outcomes beyond 5 years post-baseline. Two of the three 6- to 12-month cohort studies included a cessation intervention of some form - 7-day and 30day PPA. The third 6- to 12-month cohort study reported continuous abstinence.

In the longer-term cohort studies, results were of mixed significance. COMMIT (a community-based public health intervention conducted in 11 matched pairs of communities) assessed menthol smoking at baseline in 1988; participants were interviewed again in 1993, 1998, 2001, and 2005. Investigators found no difference between menthol, versus non-menthol, smokers and smoking cessation during 17 years of follow up. The CARDIA

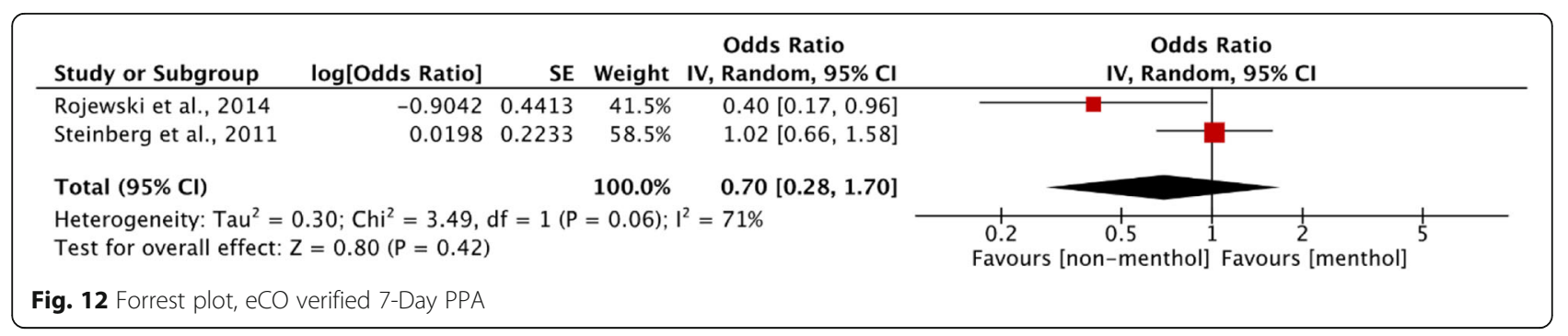


Table 10 Strength of Evidence Assessment by Measure (Adjusted Analyses)

\begin{tabular}{lllllll}
\hline & Study limitations & Directness & Consistency & Precision & SOE & CQ assessment \\
\hline Duration of abstinence & Low & Direct & Inconsistent & Precise & Low & Acceptable \\
Quit Attempts & Low & Indirect & Inconsistent & Imprecise & Insufficient & Acceptable \\
Rate of abstinence/quitting & Low & Direct & Inconsistent & Imprecise & Moderate & Acceptable \\
Change in quantity/frequency & Low & Indirect & Consistent & Imprecise & Insufficient & Acceptable \\
Return to smoking/relapse & Low & Direct & Inconsistent & Imprecise & Insufficient & Inconclusive \\
\hline
\end{tabular}

CQ Contextual Question, SOE Strength of Evidence

study, a cohort of young adults at baseline, found no association between menthol cigarette use and cessation at 15 -year follow up. However, a significantly positive association between menthol cigarette use and the risk of smoking relapse was identified. Finally, a study that investigated the association between menthol smoking and quit rate found that menthol smokers had a significantly lower likelihood of quitting compared with non-menthol smokers.

Return to smoking/relapse and change in smoking quantity/frequency were each reported by only two studies. Data were too limited to draw a reliable conclusion about the association between menthol cigarette use and either measure. Quit attempts - making at least one attempt and the number of quit attempts per person were reported by several studies, but the measure does not reflect actual cessation. Given the lack of a significant difference between menthol and non-menthol smokers on either measure of quit attempts and the empirical uncertainty of the association between making a quit attempt or the number of quit attempts and actual cessation, there is no confident conclusion that can be drawn regarding an association with menthol smoking.

Pooled data for the meta-analyses were extracted for two outcome measures, quit attempts and abstinence. Pooled results from five studies suggested a significant association between menthol cigarette use and increased odds for past year quit attempts. However, pooled data from three studies measuring ever quit attempts found no difference between menthol and non-menthol smokers in the odds of making a quit attempt. Pooling data from all eight studies revealed no consistent differences.

Additional analysis of pooled data from two studies presenting results on quit attempts among Black participants showed that Black menthol, versus non-menthol, smokers were significantly more likely to make a quit attempt. Further, pooled data from three studies suggested that White menthol, versus non-menthol, smokers were significantly less likely of making a quit attempt.

Four cohort studies presented results for examining the association between menthol use and abstinence, with no specified duration. Pooled results showed no difference between menthol and non-menthol smokers in terms of abstinence, even in sub-analyses of Black and White participants, using data from three of the four studies.

Across all four cohort studies, pooled results on the association between menthol use and abstinence, again with no specified duration, showed no difference between menthol and non-menthol smokers, overall, in the odds of abstinence. However, when measuring abstinence by 7-day PPA, pooled data suggest that Black menthol smokers were significantly less likely than Black non-menthol smokers to be abstinent. Recognizing inconsistent results were reported across studies in the qualitative synthesis, metaanalytic results, generally, showed no difference between menthol cigarette use and quit attempts (pooled results from ever, past year quit attempts, any quit attempts between 2001 to 2005, and any quit attempt in the past 2,3 , or 5 years), abstinence with no defined duration, and 7-day PPA.

Table 11 Overall Strength of Evidence Assessment (Adjusted Analyses)

\begin{tabular}{|c|c|c|c|}
\hline Measure Name & CQ Assessment & Measure SOE & Overall SOE \\
\hline Duration of abstinence & Acceptable & Low & Low \\
\hline Quit attempts & Acceptable & Insufficient & \\
\hline Rate of abstinence/quitting & Acceptable & Moderate & \\
\hline Change quantity/frequency & Acceptable & Insufficient & \\
\hline Return to smoking/relapse & Inconclusive & Insufficient & \\
\hline
\end{tabular}

CQ Contextual Question, SOE Strength of Evidence 


\section{Limitations}

This systematic review was conducted according to established methodological standards and with inherent limitations. For example, the variation in the definitions of several outcome measures made it difficult to summarize results, which limited the reviewers' ability to draw confident conclusions. Most of the smoking behavior data were self-reported. However, any differential impact of reliance on self-reported data was expected to be minimal. The Downs and Black checklist has some limitations when applied across a variety of study designs. Furthermore, a study's quality score on the Downs and Black checklist may reflect the quality of reporting rather than the quality of the study as conducted. Finally, the conclusions in this review are based on studies conducted in the U.S. and may or may not be generalizable to other countries due to the potential impact of important influences, such as cultural norms, smoking policies, and taxes on smoking behaviors outside of the U.S.

\section{Conclusions}

In summary, the findings of this systematic review suggest that the current evidence base is not strong or consistent enough to support a clear association-positive or negative-between menthol cigarette use and smoking cessation. Having comprehensively reviewed the available literature, this review-which included nearly three times the number of studies as the 2013 FDA Report and 2015 Addendum, including 16 studies that analyzed data among Black smokers only-recommends that future studies assessing the association between menthol cigarette smoking and smoking behaviors can be strengthened in several ways. Specifically, longitudinal data that measures cessation for 12 months or longer to reflect more sustained measures of cessation and adjusting for key demographic variables, at a minimum, will provide more insight into the potential association of menthol cigarette smoking and smoking cessation. Further, given the transparent, comprehensive, and objective approach taken in this review, it is the authors' hope that these findings - as well as findings from their continued monitoring of the literature-will inform future policy decision-making, as well as influence the methodological approach of future systematic reviews towards an equivalent degree of strict methodological rigor.

\footnotetext{
Abbreviations

AOR: Adjusted odds ratio; BRFSS: Behavioral Risk Factor Surveillance System; CARDIA: Coronary Artery Risk Development in Young Adults; Cl: Confidence interval; COMMIT: Community Intervention Trial for Smoking Cessation; CPD: Cigarettes per day; CQ: Contextual Question; EPC: Evidence-Based Practice Center; HR: Hazard ratio; ITC-4: International Tobacco Control Four Country Survey; KIS: Kick it at Swope; KQ: Key Question; LYAC: Legacy Young Adult Cohort Study; NA: Not Applicable; NHIS: National Health Interview Survey; NHIS-CCS: National Health Interview Survey Cancer Control Supplement; PA: Prolonged abstinence; PATH: Population Assessment of Tobacco and Health; POR : Prevalence odds ratio; PPA: Point (or period)
}

prevalence abstinence; PR: Prevalence ratio; SE: Standard error; SOE : Strength of Evidence; TUS-CPS: The Tobacco Use Supplement to the Current Population Survey; U.S.: United States; WSHS: Wisconsin Smokers Health Study

\section{Supplementary Information}

The online version contains supplementary material available at https://doi. org/10.1186/s13011-021-00397-4.

Additional file 1. Literature Search Strategy.

Additional file 2. Studies excluded at full-text level screening (with reason for exclusion).

Additional file 3. Outcome Measures for Smoking Cessation across Adjusted Studies.

Additional file 4 Evidence Table, Modeled / Adjusted Results (Duration of Abstinence, Any Quit Attempt, Number of Quit Attempts per Person, Rate of Abstinence/Quitting, Change in Smoking Quantity/Frequency, and Return to Smoking/Relapse) ( $n=43$ studies; $n=47$ references).

Additional file 5. Sensitivity Analyses.

Additional file 6. Characteristics, Definitions, and Covariates of Studies Included in the Meta-Analysis.

\section{Acknowledgements}

The authors would like to acknowledge the Venebio Group, LLC (Richmond, VA) for providing their systematic review expertise to execute the original synthesis of the evidence base and all study activities across all levels of the review process. The authors also acknowledge Thera-Business (Ontario

(ANADA) for providing their systematic review expertise to all study activities across all levels of the updated review process.

\section{Authors' contributions}

M.K. and G.C. co-lead the conceptualization of this review and served as subject matter experts throughout the review process. M.K. led the preparation and finalization of the manuscript. G.C. served as the second author for all aspects of the manuscript preparation process including critically revising the manuscript and reviewing accuracy of all technical details. The corresponding author attests that the listed authors meet authorship criteria and that no others meeting the criteria have been omitted. The author(s) read and approved the final manuscript.

\section{Funding}

All study activities were executed by providers external to RAI Services Company (Venebio and Thera-Business). These providers were financially compensated for services according to contractual terms with RAI Services Company. RAI Services Company is a wholly owned subsidiary of Reynolds American Inc., whose operating companies manufacture and market tobacco products. Reynolds American Inc. was acquired by British American Tobacco in July 2017.

Availability of data and materials

All data and materials considered in this review are publicly available.

\section{Declarations}

Consent for publications

Not applicable.

Ethics approval and consent to participate Not applicable.

\section{Competing interests}

Both Drs. Kim and Curtin serve as full-time employees of RAI Services Company, a wholly owned subsidiary of Reynolds American Inc., a manufacturer and marketer of tobacco products. 
Accepted: 27 July 2021

Published online: 11 August 2021

\section{References}

1. Caraballo RS, Asman K. Epidemiology of menthol cigarette use in the United States. Tob Induc Dis. 2011;9(Suppl 1):S1.

2. Centers for Disease Control and Prevention. Current Cigarette Smoking Among Adults - United States, 2011 Nov 9, 2012 [Available from: https:// www.cdc.gov/mmwr/preview/mmwrhtml/mm6144a2.htm].

3. Substance Abuse and Mental Health Services Administration. The NSDUH Report: Recent Trends in Menthol Cigarette Use. Rockville: Substance Abuse and Mental Health Services Administration, Center for Behavioral Health Statistics and Quality; 2011.

4. Administration UFaD. FDA commits to evidence-based actions aimed at saving lives and preventing future generations of smokers. Washington D.C US Food and Drug Administration; 2021. [updated 29 April. Available from: https://www.fda.gov/news-events/press-announcements/fda-commitsevidence-based-actions-aimed-saving-lives-and-preventing-future-genera tions-smokers]

5. Tobacco Products Scientific Advisory Committee. Menthol Report and Recommendation 2011 [Available from: http://www.fda.gov/downloads/A dvisoryCommittees/CommitteesMeetingMaterials/Toba ccoProductsScientificAdvisoryCommittee/UCM269697.pdf].

6. U.S. Food and Drug Administration. Preliminary scientific evaluation of the possible public health effects of menthol versus nonmenthol cigarettes 2013 [Available from: http://www.fda.gov/downloads/ScienceResearch/ SpecialTopics/PeerReviewofScientificlnformationandAssessments/UCM361 598.pdf].

7. U.S. Food and Drug Administration. Reference addendum: preliminary scientific evaluation of the possible public health effects of menthol versus non-menthol cigarettes 2015 [Available from: http://www.fda.gov/downloa ds/ScienceResearch/SpecialTopics/PeerReviewofScientificlnformationandA ssessments/UCM362600.pdf].

8. Stanton CA, Papandonatos G, Lloyd-Richardson EE, Niaura R. Consistency of self-reported smoking over a 6-year interval from adolescence to young adulthood. Addiction. 2007;102(11):1831-9. https://doi.org/10.1111/j.13600443.2007.01974.x

9. Soulakova JN, Hartman AM, Liu B, Willis GB, Augustine S. Reliability of adult self-reported smoking history: data from the tobacco use supplement to the current population survey 2002-2003 cohort. Nicotine Tob Res. 2012 14(8):952-60. https://doi.org/10.1093/ntr/ntr313.

10. Smith PH, Assefa B, Kainth S, Salas-Ramirez KY, McKee SA, Giovino GA. Use of mentholated cigarettes and likelihood of smoking cessation in the United States: a meta-analysis. Nicotine Tob Res. 2020;22(3):307-16.

11. Kandel DB, Kiros G-E, Schaffran C, Hu M-C. Racial/ethnic differences in cigarette smoking initiation and progression to daily smoking: a multilevel analysis. Am J Public Health. 2004;94(1):128-35. https://doi.org/10.2105/A JPH.94.1.128.

12. Yi Z, Mayorga ME, Hassmiller Lich K, Pearson JL. Changes in cigarette smoking initiation, cessation, and relapse among U.S. adults: a comparison of two longitudinal samples. Tobacco Induced Dis. 2017;15:17.

13. McLeroy KR, Bibeau D, Steckler A, Glanz K. An ecological perspective on health promotion programs. Health Educ Q. 1988;15(4):351-77. https://doi. org/10.1177/109019818801500401.

14. Downs SH, Black N. The feasibility of creating a checklist for the assessment of the methodological quality both of randomised and non-randomised studies of health care interventions. J Epidemiol Community Health. 1998; 52(6):377-84. https://doi.org/10.1136/jech.52.6.377.

15. International Agency for Research on Cancer. Section 3.3 Measurement of nicotine dependence. Methods for Evaluating Tobacco Control Policies IARC Handbook of Cancer Prevention, vol. 12. Lyon: World Health Organization; 2008

16. DerSimonian R, Laird N. Meta-analysis in clinical trials. Control Clin Trials. 1986;7(3):177-88. https://doi.org/10.1016/0197-2456(86)90046-2.

17. Higgins JP, Thompson SG. Quantifying heterogeneity in a meta-analysis. Stat Med. 2002;21(11):1539-58. https://doi.org/10.1002/sim.1186.

18. The Nordic Cochrane Centre. Review manager (RevMan). The Cochrane collaboration. 5.3 ed. Copenhagen: The Cochrane Collaboration; 2014.

19. Wells GA, Shea B, Higgins JP, Sterne J, Tugwell P, Reeves BC. Checklists of methodological issues for review authors to consider when including nonrandomized studies in systematic reviews. Res Synth Methods. 2013:4(1):6377. https://doi.org/10.1002/jrsm.1077.
20. Schunemann HJ, Tugwell P, Reeves BC, Akl EA, Santesso N, Spencer FA, et al. Non-randomized studies as a source of complementary, sequential or replacement evidence for randomized controlled trials in systematic reviews on the effects of interventions. Res Synth Methods. 2013;4(1):49-62. https:// doi.org/10.1002/jrsm.1078.

21. Norris SL, Moher D, Reeves BC, Shea B, Loke $Y$, Garner S, et al. Issues relating to selective reporting when including non-randomized studies in systematic reviews on the effects of healthcare interventions. Res Synth Methods. 2013; 4(1):36-47. https://doi.org/10.1002/jrsm.1062.

22. Higgins JP, Ramsay C, Reeves BC, Deeks JJ, Shea B, Valentine JC, et al. Issues relating to study design and risk of bias when including non-randomized studies in systematic reviews on the effects of interventions. Res Synth Methods. 2013:4(1):12-25. https://doi.org/10.1002/jrsm.1056.

23. Group GW. Grading quality of evidence and strength of recommendations. BMJ. 2004:328(7454):1490.

24. Berkman ND, Lohr KN, Ansari MT, Balk EM, Kane R, McDonagh M, et al. Grading the strength of a body of evidence when assessing health care interventions: an EPC update. J Clin Epidemiol. 2015;68(11):1312-24. https:// doi.org/10.1016/j.jclinepi.2014.11.023.

25. Alexander LA, Crawford T, Mendiondo MS. Occupational status, work-site cessation programs and policies and menthol smoking on quitting behaviors of US smokers. Addiction. 2010;105(Suppl 1):95-104. https://doi. org/10.1111/j.1360-0443.2010.03227.x.

26. Azagba S, King J, Shan L, Manzione L. Cigarette smoking behavior among menthol and nonmenthol adolescent smokers. J Adolesc Health. 2020;66(5): 545-50. https://doi.org/10.1016/j.jadohealth.2019.11.307.

27. Blot WJ, Cohen SS, Aldrich M, MCLaughlin JK, Hargreaves MK, Signorello LB. Lung cancer risk among smokers of menthol cigarettes. J Natl Cancer Inst. 2011;103(10):810-6. https://doi.org/10.1093/jnci/djr102.

28. Cropsey KL, Weaver MF, Eldridge GD, Villalobos GC, Best AM, Stitzer ML. Differential success rates in racial groups: results of a clinical trial of smoking cessation among female prisoners. Nicotine Tob Res. 2009;11(6):690-7. https://doi.org/10.1093/ntr/ntp051.

29. Cubbin C, Soobader MJ, LeClere FB. The intersection of gender and race/ ethnicity in smoking behaviors among menthol and non-menthol smokers in the United States. Addiction. 2010;105(Suppl 1):32-8. https://doi.org/1 0.1111/j.1360-0443.2010.03191.x.

30. D'Silva J, Boyle RG, Lien R, Rode P, Okuyemi KS. Cessation outcomes among treatment-seeking menthol and nonmenthol smokers. Am J Prev Med. 2012;43(5 Suppl 3):S242-8. https://doi.org/10.1016/j.amepre.2012.07.033.

31. Delnevo CD, Gundersen DA, Hrywna M. Examining the relationship between menthol smoking and cessation using data from the 2003 and 2006/7 Tobacco Use Supplement: Center for Tobacco Surveillance and Evaluation Researc. New Jersey: University of Medicine \& Dentistry of New Jersey - School of Public Health; 2010. p. 2011.

32. Delnevo CD, Gundersen DA, Hrywna M, Echeverria SE, Steinberg MB. Smoking-cessation prevalence among U.S. smokers of menthol versus nonmenthol cigarettes. Am J Prev Med. 2011;41(4):357-65. https://doi.org/10.1 016/j.amepre.2011.06.039.

33. Fagan $\mathrm{P}$, Augustson E, Backinger CL, O'Connell ME, Vollinger RE Jr, Kaufman $A$, et al. Quit attempts and intention to quit cigarette smoking among young adults in the United States. Am J Public Health. 2007;97(8):1412-20. https://doi.org/10.2105/AJPH.2006.103697.

34. Faseru B, Nollen NL, Mayo MS, Krebill R, Choi WS, Benowitz NL, et al. Predictors of cessation in African American light smokers enrolled in a bupropion clinical trial. Addict Behav. 2013;38(3):1796-803. https://doi.org/1 0.1016/j.addbeh.2012.11.010

35. Foulds J, Gandhi KK, Steinberg MB, Richardson DL, Williams JM, Burke MV, et al. Factors associated with quitting smoking at a tobacco dependence treatment clinic. Am J Health Behav. 2006;30(4):400-12. https://doi.org/10. 5993/AJHB.30.4.6.

36. Fu SS, Okuyemi KS, Partin MR, Ahluwalia JS, Nelson DB, Clothier BA, et al. Menthol cigarettes and smoking cessation during an aided quit attempt. Nicotine Tob Res. 2008;10(3):457-62. https://doi.org/10.1080/14622200801 901914

37. Gandhi KK, Foulds J, Steinberg MB, Lu SE, Williams JM. Lower quit rates among African American and Latino menthol cigarette smokers at a tobacco treatment clinic. Int J Clin Pract. 2009;63(3):360-7. https://doi.org/1 0.1111/j.1742-1241.2008.01969.x.

38. Gubner NR, Williams DD, Pagano A, Campbell BK, Guydish J. Menthol cigarette smoking among individuals in treatment for substance use 
disorders. Addict Behav. 2018;80:135-41. https://doi.org/10.1016/j.addbeh.2 018.01.015.

39. Gundersen DA, Delnevo CD, Wackowski O. Exploring the relationship between race/ethnicity, menthol smoking, and cessation, in a nationally representative sample of adults. Prev Med. 2009;49(6):553-7. https://doi. org/10.1016/j.ypmed.2009.10.003.

40. Hyland A, Garten S, Giovino GA, Cummings KM. Mentholated cigarettes and smoking cessation: findings from COMMIT. Tob Control. 2002;11(2):135-9. https://doi.org/10.1136/tc.11.2.135.

41. Hyland A, Rivard C. Analysis of mentholated cigarettes using the COMMIT data -- summary. New York: Department of Health Behavior, Roswell Park Cancer Institute; 2010.

42. Kahende JW, Malarcher AM, Teplinskaya A, Asman KJ. Quit attempt correlates among smokers by race/ethnicity. Int J Environ Res Public Health. 2011;8(10):3871-88. https://doi.org/10.3390/ijerph8103871.

43. Kasza KA, Hyland AJ, Bansal-Travers M, Vogl LM, Chen J, Evans SE, et al. Switching between menthol and nonmenthol cigarettes: findings from the U.S. cohort of the international tobacco control four country survey. Nicotine Tob Res. 2014;16(9):1255-65. https://doi.org/10.1093/ntr/ntu098.

44. Keeler C, Max W, Yerger V, Yao T, Ong MK, Sung H-Y. The Association of menthol cigarette use with quit attempts, successful cessation, and intention to quit across racial/ethnic groups in the United States. Nicotine Tob Res. 2017;19(12):1450-64. https://doi.org/10.1093/ntr/ntw215.

45. Keeler C, Max W, Yerger VB, Yao T, Wang Y, Ong MK, et al. Effects of cigarette prices on intention to quit, quit attempts, and successful cessation among African American smokers. Nicotine Tob Res. 2020;22(4):522-31.

46. Levy DT, Blackman K, Tauras J, Chaloupka FJ, Villanti AC, Niaura RS, et al. Quit attempts and quit rates among menthol and nonmenthol smokers in the United States. Am J Public Health. 2011;101(7):1241-7. https://doi.org/1 0.2105/AJPH.2011.300178.

47. Lewis M, Wang Y, Berg CJ. Tobacco control environment in the United States and individual consumer characteristics in relation to continued smoking: differential responses among menthol smokers? Prev Med. 2014; 65:47-51. https://doi.org/10.1016/j.ypmed.2014.04.019.

48. Muench C, Juliano LM. Predictors of smoking lapse during a 48-hour laboratory analogue smoking cessation attempt. Psychol Addict Behav. 2017;31(4):415-22. https://doi.org/10.1037/adb0000246.

49. Muscat JE, Richie JP Jr, Stellman SD. Mentholated cigaettes and smoking habits in whites and blacks. Tob Control. 2002;11(4):368-71. https://doi.org/1 0.1136/tc. 11.4.368.

50. Nonnemaker J, Hersey J, Homsi G, Busey A, Allen J, Vallone D. Initiation with menthol cigarettes and youth smoking uptake. Addiction. 2012;108(1):1718. https://doi.org/10.1111/j.1360-0443.2012.04045.x.

51. Okuyemi KS, Ahluwalia JS, Ebersole-Robinson M, Catley D, Mayo MS, Resnicow K. Does menthol attenuate the effect of bupropion among African American smokers? Addiction. 2003;98(10):1387-93. https://doi.org/1 0.1046/j.1360-0443.2003.00443.x.

52. Okuyemi KS, Faseru B, Sanderson Cox L, Bronars CA, Ahluwalia JS. Relationship between menthol cigarettes and smoking cessation among African American light smokers. Addiction. 2007;102(12):1979-86. https://doi. org/10.1111/j.1360-0443.2007.02010.x

53. Park J-Y. Tobacco use behaviors among vulnerable populations. Dissertation Abstracts Int: Section B: Sci Eng. 2017;77(12-B(E)):No-Specified.

54. Pletcher MJ, Hulley BJ, Houston T, Kiefe Cl, Benowitz N, Sidney S. Menthol cigarettes, smoking cessation, atherosclerosis, and pulmonary function. Arch Intern Med. 2006;166(17):1915-22. https:/doi.org/10.1001/archinte.166.17.1915.

55. Rath JM, Villanti AC, Williams VF, Richardson A, Pearson JL, Vallone DM. Patterns of longitudinal transitions in menthol use among US young adult smokers. Nicotine Tob Res. 2015;17(7):839-46. https://doi.org/10.1093/ntr/ntu247.

56. Reitzel LR. Menthol cigarettes, tobacco dependence, and smoking cessation: project BREAK FREE final report; 2011.

57. Reitzel LR. Menthol cigarettes, tobacco dependence, and smoking cessation: project CARE final report; 2011.

58. Reitzel LR. Menthol cigarettes, tobacco dependence, and smoking cessation: project MOM final report; 2011.

59. Reitzel LR, Nguyen N, Cao Y, Vidrine Jl, Daza P, Mullen PD, et al. Race/ ethnicity moderates the effect of prepartum menthol cigarette use on postpartum smoking abstinence. Nicotine Tob Res. 2011;13(12):1305-10. https://doi.org/10.1093/ntr/ntr095.

60. Reitzel LR, Li Y, Stewart DW, Cao Y, Wetter DW, Waters AJ, et al. Race moderates the effect of menthol cigarette use on short-term smoking abstinence. Nicotine Tob Res. 2013;15(5):883-9. https://doi.org/10.1093/ntr/ nts335.

61. Rojewski AM, Toll BA, O'Malley SS. Menthol cigarette use predicts treatment outcomes of weight-concerned smokers. Nicotine Tob Res. 2014;16(1):1159. https://doi.org/10.1093/ntr/ntt137.

62. Sawdey MD, Chang JT, Cullen KA, Rass O, Jackson K, Ali FRM, et al. Trends and associations of menthol cigarette smoking among US middle and high school students-National Youth Tobacco Survey, 2011-2018. Nicotine Tob Res. 2020;22(10):1726-35. https://doi.org/10.1093/ntr/ntaa054.

63. Schneller LM. Assessment of various delivery methods of menthol in cigarettes sold in the US. Cancer Science, Roswell Park Graduate Division; 2019.

64. Schneller LM, Bansal-Travers M, Mahoney MC, McCann SE, O'Connor RJ. Menthol cigarettes and smoking cessation among adult smokers in the US. Am J Health Behav. 2020;44(2):252-6. https://doi.org/10.5993/AJHB.44.2.12.

65. Stahre M, Okuyemi KS, Joseph AM, Fu SS. Racial/ethnic differences in menthol cigarette smoking, population quit ratios and utilization of evidence-based tobacco cessation treatments. Addiction. 2010;105(Suppl 1): 75-83. https://doi.org/10.1111/j.1360-0443.2010.03200.x.

66. Steinberg MB, Bover MT, Richardson DL, Schmelzer AC, Williams JM, Foulds $J$. Abstinence and psychological distress in co-morbid smokers using various pharmacotherapies. Drug Alcohol Depend. 2011;114(1):77-81. https://doi. org/10.1016/j.drugalcdep.2010.06.022.

67. Sulsky SI, Fuller WG, Van Landingham C, Ogden MW, Swauger JE, Curtin GM. Evaluating the association between menthol cigarette use and the likelihood of being a former versus current smoker. Regul Toxicol Pharmacol. 2014;70(1):231-41. https://doi.org/10.1016/j.yrtph.2014.07.009.

68. Thihalolipavan S, Jung M, Jasek J, Chamany S. Menthol smokers in largescale nicotine replacement therapy program. Am J Public Health. 2014; 104(11):e3-4. https://doi.org/10.2105/AJPH.2014.302168.

69. Trinidad DR, Perez-Stable EJ, Messer K, White MM, Pierce JP. Menthol cigarettes and smoking cessation among racial/ethnic groups in the United States. Addiction. 2010;105(Suppl 1):84-94. https://doi.org/10.1111/j.13600443.2010.03187.x.

70. Webb Hooper M, Zhao W, Byrne MM, Davila E, Caban-Martinez A, Dietz NA, et al. Menthol cigarette smoking and health, Florida 2007 BRFSS. Am J Health Behav. 2011:31(1):3-14.

71. Winhusen TM, Adinoff B, Lewis DF, Brigham GS, Gardin JG 2nd, Sonne SC, et al. A tale of two stimulants: mentholated cigarettes may play a role in cocaine, but not methamphetamine, dependence. Drug Alcohol Depend. 2013;133(3):845-51. https://doi.org/10.1016/j.drugalcdep.2013.09.002.

72. Brigham J, Lessov-Schlaggar CN, Javitz HS, Krasnow RE, McElroy M, Swan GE. Test-retest reliability of web-based retrospective self-report of tobacco exposure and risk. J Med Internet Res. 2009;11(3):e35. https://doi.org/10.21 96/jmir.1248.

73. Colby SM, Clark MA, Rogers ML, Ramsey S, Graham AL, Boergers J, et al. Development and reliability of the lifetime interview on smoking trajectories. Nicotine Tob Res. 2012;14(3):290-8. https:/doi.org/10.1093/ntr/ntr212.

74. Borland R, Yong HH, O'Connor RJ, Hyland A, Thompson ME. The reliability and predictive validity of the heaviness of smoking index and its two components: findings from the international tobacco control four country study. Nicotine Tob Res. 2010;12(Suppl):S45-50. https:/doi.org/10.1093/ntr/ntq038.

75. Brener ND, Kann L, McManus T, Kinchen SA, Sundberg EC, Ross JG. Reliability of the 1999 youth risk behavior survey questionnaire. J Adolesc Health. 2002;31 (4):336-42. https://doi.org/10.1016/S1054-139X(02)00339-7.

76. Brigham J, Lessov-Schlaggar CN, Javitz HS, Krasnow RE, Tildesley E, Andrews $J$, et al. Validity of recall of tobacco use in two prospective cohorts. Am J Epidemiol. 2010;172(7):828-35. https://doi.org/10.1093/aje/kwq179.

77. Hughes JR, Carpenter MJ, Naud S. Do point prevalence and prolonged abstinence measures produce similar results in smoking cessation studies? A systematic review. Nicotine Tob Res. 2010;12(7):756-62. https://doi.org/1 0.1093/ntr/ntq078.

78. Velicer WF, Prochaska JO. A comparison of four self-report smoking cessation outcome measures. Addict Behav. 2004;29(1):51-60. https://doi. org/10.1016/50306-4603(03)00084-4.

79. Rahman A, Mohamad MHN, Jamshed S. Evaluating effectiveness and safety toward electronic cigarette among Malaysian vapers: one-month observational study. Arch Pharma Pract. 2016;7(2):43. https://doi.org/10.41 03/2045-080X.181038.

80. Abrams DB, Follick MJ, Biener L, Carey KB, Hitti J. Saliva cotinine as a measure of smoking status in field settings. Am J Public Health. 1987:77(7): 846-8. https://doi.org/10.2105/AJPH.77.7.846. 
81. From Attebring M, Herlitz J, Berndt AK, Karlsson T, Hjalmarson A. Are patients truthful about their smoking habits? A validation of self-report about smoking cessation with biochemical markers of smoking activity amongst patients with ischaemic heart disease. J Intern Med. 2001;249(2): 145-51. https://doi.org/10.1046/j.1365-2796.2001.00770.x.

82. Bender D, Haubruck P, Boxriker S, Korff S, Schmidmaier G, Moghaddam A. Validity of subjective smoking status in orthopedic patients. Ther Clin Risk Manag. 2015;11:1297-303. https://doi.org/10.2147/TCRM.S86212.

83. Gerritsen M, Berndt N, Lechner L, de Vries H, Mudde A, Bolman C. Selfreporting of smoking cessation in cardiac patients: how reliable is it and is reliability associated with patient characteristics? J Addict Med. 2015;9(4): 308-16. https://doi.org/10.1097/ADM.0000000000000137.

84. Hilberink SR, Jacobs JE, Breteler MH, de Vries H, Grol RP. General practice counseling for patients with chronic obstructive pulmonary disease to quit smoking: impact after 1 year of two complex interventions. Patient Educ Couns. 2011;83(1):120-4. https://doi.org/10.1016/j.pec.2010.04.009.

85. Studts JL, Ghate SR, Gill JL, Studts CR, Barnes CN, LaJoie AS, et al. Validity of self-reported smoking status among participants in a lung cancer screening trial. Cancer Epidemiol Biomark Prev. 2006;15(10):1825-8. https://doi.org/1 0.1158/1055-9965.EPI-06-0393.

86. Tourangeau R, Yan T, Sun H, Hyland A, Stanton CA. Population Assessment of Tobacco and Health (PATH) reliability and validity study: selected reliability and validity estimates. Tob Control. 2019;28(6):663-8.

87. van der Aalst $\mathrm{CM}$, de Koning HJ. Biochemical verification of the selfreported smoking status of screened male smokers of the Dutch-Belgian randomized controlled lung cancer screening trial. Lung Cancer. 2016;94: 96-101. https://doi.org/10.1016/j.lungcan.2016.02.001.

88. Hymowitz N, Cummings KM, Hyland A, Lynn WR, Pechacek TF, Hartwell TD. Predictors of smoking cessation in a cohort of adult smokers followed for five years. Tob Control. 1997;6(Suppl 2):S57-62. https://doi.org/10.1136/tc.6.suppl_2.S57.

89. Rohsenow DJ, Martin RA, Tidey JW, Monti PM, Colby SM. Comparison of the cigarette dependence scale with four other measures of nicotine involvement: correlations with smoking history and smoking treatment outcome in smokers with substance use disorders. Addict Behav. 2013;38(8): 2409-13. https://doi.org/10.1016/j.addbeh.2013.03.019.

90. Brozek G, Jankowski M, Zejda J, Jarosinska A, Idzik A, Banka P. E-smoking among students of medicine - frequency, pattern and motivations. Adv Respir Med. 2017:85(1):8-14. https://doi.org/10.5603/ARM.2017.0003.

91. Grant BF, Dawson DA, Stinson FS, Chou PS, Kay W, Pickering R. The alcohol use disorder and associated disabilities interview schedule-IV (AUDADIS-IV): reliability of alcohol consumption, tobacco use, family history of depression and psychiatric diagnostic modules in a general population sample. Drug Alcohol Depend. 2003;71(1):7-16. https://doi.org/10.1016/50376-8716(03 )00070-X.

92. Ramo DE, Hall SM, Prochaska JJ. Reliability and validity of self-reported smoking in an anonymous online survey with young adults. Health Psychol. 2011;30(6):693-701. https://doi.org/10.1037/a0023443.

93. Stanton WR, McClelland M, Elwood C, Ferry D, Silva PA. Prevalence, reliability and bias of adolescents' reports of smoking and quitting. Addiction. 1996;91(11):1705-14. https://doi.org/10.1111/j.1360-0443.1996. tb02273.x

94. Blank MD, Breland AB, Enlow PT, Duncan C, Metzger A, Cobb CO. Measurement of smoking behavior: Comparison of self-reports, returned cigarette butts, and toxicant levels. Exp Clin Psychopharmacol. 2016;24(5): 348-55.

95. Weinberger AH, Reutenauer EL, Allen TM, Termine A, Vessicchio JC, Sacco $\mathrm{KA}$, et al. Reliability of the Fagerstrom test for nicotine dependence, Minnesota nicotine withdrawal scale, and Tiffany questionnaire for smoking urges in smokers with and without schizophrenia. Drug Alcohol Depend. 2007;86(2-3):278-82. https://doi.org/10.1016/j.drugalcdep.2006.06.005.

96. Rostron BL, Corey CG, Chang JT, van Bemmel DM, Miller ME, Chang CM. Associations of cigarettes smoked per day with biomarkers of exposure among U.S. Adult cigarette smokers in the Population Assessment of Tobacco and Health (PATH) Study Wave 1 (2013-2014). Cancer Epidemiol Biomark Prev. 2019;28(9):1443

\section{Publisher's Note}

Springer Nature remains neutral with regard to jurisdictional claims in published maps and institutional affiliations.

Ready to submit your research? Choose BMC and benefit from:

- fast, convenient online submission

- thorough peer review by experienced researchers in your field

- rapid publication on acceptance

- support for research data, including large and complex data types

- gold Open Access which fosters wider collaboration and increased citations

- maximum visibility for your research: over $100 \mathrm{M}$ website views per year

At BMC, research is always in progress.

Learn more biomedcentral.com/submissions 